Library, E-vi min. Bldg.

JUN 211968

NBS MONOGRAPH 110

\title{
Infrared Spectroscopy
}

Of Carbohydrates

A Review of the Literature

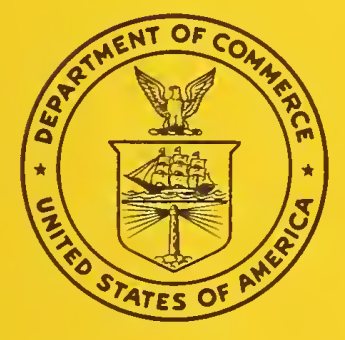

U.S. DEPARTMENT OF COMMERCE

NATIONAL BUREAU OF STANDARDS 


\section{THE NATIONAL BUREAU OF STANDARDS}

The National Bureau of Standards ${ }^{1}$ provides measurement and technical information services essential to the efficiency and effectiveness of the work of the Nation's scientists and engineers. The Bureau serves also as a focal point in the Federal Government for assuring maximum application of the physical and engineering sciences to the advancement of technology in industry and commerce. To accomplish this mission, the Bureau is organized into three institutes covering broad program areas of research and services:

THE INSTITUTE FOR BASIC STANDARDS . . . provides the central basis within the United States for a complete and consistent system of physical measurements, coordinates that system with the measurement systems of other nations, and furnishes essential services leading to accurate and uniform physical measurements throughout the Nation's scientific community, industry, and commerce. This Institute comprises a series of divisions, each serving a classical subject matter area:

-Applied Mathematics-Electricity-Metrology-Mechanics-Heat-Atomic Physics-Physical Chemistry-Radiation Physics-Laboratory Astrophysics ${ }^{2}$ - Radio Standards Laboratory, ${ }^{2}$ which includes Radio Standards Physics and Radio Standards Engineering-Office of Standard Reference Data.

THE INSTITUTE FOR MATERIALS RESEARCH . . . conducts materials research and provides associated materials services including mainly reference materials and data on the properties of materials. Beyond its direct interest to the Nation's scientists and engineers, this Institute yields services which are essential to the advancement of technology in industry and commerce. This Institute is organized primarily by technical fields:

-Analytical Chemistry-Metallurgy-Reactor Radiations-Polymers-Inorganic Materials-Cryogenics $^{2}$ - Office of Standard Reference Materials.

THE INSTITUTE FOR APPLIED TECHNOLOGY . . . provides technical services to promote the use of available technology and to facilitate technological innovation in industry and government. The principal elements of this Institute are:

-Building Research-Electronic Instrumentation-Technical Analysis-Center for Computer Sciences and Technology-Textile and Apparel Technology Center-Office of Weights and Measures -Office of Engineering Standards Services-Office of Invention and Innovation-Office of Vehicle Systems Research-Clearinghouse for Federal Scientific and Technical Information ${ }^{3}$-Materials Evaluation Laboratory-NBS/GSA Testing Laboratory.

\footnotetext{
${ }^{1}$ Headquarters and Laboratories at Gaithersburg, Maryland, unless otherwise noted; mailing address Washington, D. C. 20234.

2 Located at Boulder, Colorado 80302.

${ }^{3}$ Located at 5285 Port Royal Road, Springfield, Virginia 22151.
} 
UNITED STATES DEPARTMENT OF COMMERCE

C. R. Smith, Secretary

NATIONAL BUREAU OF STANDARDS - A. V. Astin, Director

\title{
Infrared Spectroscopy of Carbohydrates
}

\section{A Review of the Literature}

\author{
R. Stuart Tipson \\ Institute for Materials Research \\ National Bureau of Standards \\ Washington, D.C. 20234
}

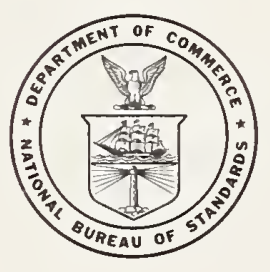

National Bureau of Standards Monograph 110 Issued June 1968 
Library of Congress Catalog Card Number: 68-60029 


\section{Contents}

2. Principles and instrumentation

3. Sampling techniques

3.1. Phase_..._.

3.2. Comparison of samples_._.

4. Interpretation of spectra

4.1. General

4.2. Functional groups in carbohydrates and their derivatives_____._.

4.2.1. C-H bands _......................................... 8

4.2.2. $\mathrm{N}-\mathrm{H}$ bands $\ldots \ldots \ldots \ldots \ldots$

4.2.3. O-H bands _......................................... 10

4.2.4. $\mathrm{C} \equiv \mathrm{C}$ and $\mathrm{C}=\mathrm{C}$ bands $\ldots \ldots \ldots \ldots$

4.2.5. $\mathrm{C} \equiv \mathrm{N}, \mathrm{C}=\mathrm{N}$, and $\mathrm{C}-\mathrm{N}$ bands $\ldots \ldots \ldots \ldots$

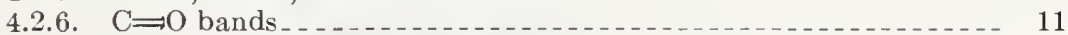

(a) Aldehydes and ketones.......................... 11

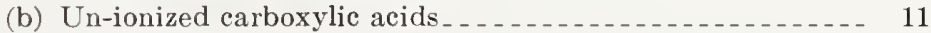

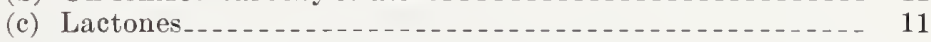

(d) Acetates and other esters .......................... 11

(e) Primary amides................................. 12

(f) $N$-Acetyl and $S$-acetyl

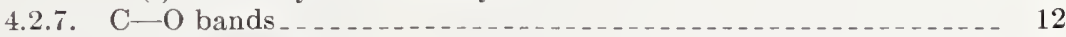

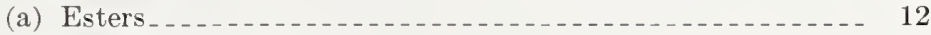

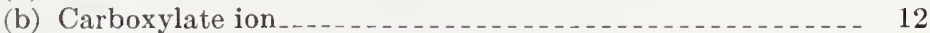

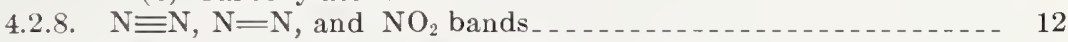

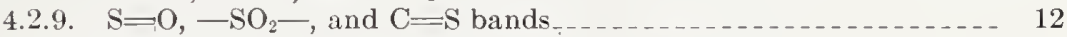

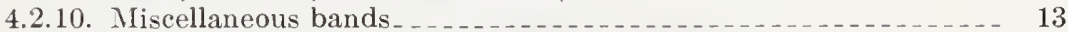

4.3. Correlations for the fingerprint region and beyond

4.3.1. The fingerprint region_..._.

4.3.2. Correlations for 10 to $15 \mu \mathrm{m}\left(1000\right.$ to $\left.667 \mathrm{~cm}^{-1}\right) \ldots \ldots \ldots$

(a) Correlations for certain aldopyranose derivatives_....... 13

(b) Correlations for furanoid and pyranoid forms of aldose and ketose derivatives ............................... 14

4.4. Conformational studies.

5. Examples of use of infrared spectra

¡.1. Qualitative $\ldots \ldots \ldots \ldots$

5.2. Quantitative_...

j.3. Determination of structure

6. Special techniques _

7. References................ 



\title{
Infrared Spectroscopy of Carbohydrates
}

\section{A Review of the Literature}

\author{
R. Stuart Tipson ${ }^{1}$
}

\begin{abstract}
A survey has been made of the literature on the infrared spectroscopy of carbohydrates, in order to assemble and systematize information in this field. The Monograph discusses principles and instrumentation, sampling techniques, comparison of samples, and the interpretation of the spectra, particularly as regards functional groups of carbohydrates and their derivatives, correlations for the fingerprint region and beyond, and conformational studies. In addition, examples are discussed of the use of infrared spectra for qualitative and quantitative purposes and in the determination of structure. Special techniques are briefly described, including use of plane-polarized radiation, the technique of attenuated total reflection, and Raman spectra.
\end{abstract}

Key Words: Analysis, carbohydrates, conformations, infrared spectra, spectrometry, structure.

\section{Introduction}

Although a large number of books on the infrared spectroscopy of organic compounds have been written $[1],{ }^{2}$ detailed attention has not been accorded in them to carbohydrates and their derivatives. Several books contain chapters on the subject, but these chapters are no longer up to date, and contain certain statements that are open to misinterpretation. Consequently, it was decided that a detailed survey should be made of the literature on the infrared spectroscopy of the carbohydrates and their derivatives, and that the information should be assembled in a readily available form.

\section{Principles and Instrumentation}

A molecule can exist in a number of energy levels, and a change from one level to another can result from absorption, or in emission, of energy, if selection rules permit this. Of the three kinds of molecular spectra, namely, electronic, rotational, and vibrational, the last kind are obtained when absorption of radiant energy causes changes in the energy of molecular vibration. Most of the vibrational absorption bands [1] are found in the range ${ }^{3}$ from 2 to $100 \mu \mathrm{m}(5000$ to $\left.100 \mathrm{~cm}^{-1}\right)$; but, as the spectrometers usually available to the organic chemist cover the range

I The author thanks Frank S. Parker, of the Department of Biochemistiy, New York Medical College, New York, and James E. Stewart, of Beckman Instruments, Inc., Fullerton, California, for a number of helpful suggestions. This Monograph is, in part, an outgrowth of a comprehensive investigation of the infrared absorption spectra of sugars and sugar derivatives begun at the National Bureau of Standards in 1949. The early work, sponsored by the Office of Naval Research, was conducted by E. C. Creitz, II. L. Frush, H. S. Isbell. J. D. Moyer. F. A. Smith, J. E. Stewart. and R. S. Tipson.

Figures in brackets indicate the literature references at the end of this Monograph.

${ }^{3}$ The position of a band in this region of the spectrum is expressed in two ways: (a) as the wavelength $(\lambda)$ in $\mu \mathrm{m}$ (micrometers; $1 \mu \mathrm{m}=10^{-6} \mathrm{~m}$, commonly called microns $(\mu)$ ], or (b) as the wavenumber $(\nu)$ in reciprocal centimeters (kaysers). The velocity of light $\left(c\right.$, in $\left.\mathrm{cms}^{-1}\right)$ is equal to the wavelength of one vibration times the number of vibrations per second; that is, $c=\lambda \nu$. The wavenumber is the reciprocal of the wavelength; thus, $\nu$ (in $\left.\mathrm{cm}^{-1}\right)=1 / \lambda$ (in $\mathrm{cm})$, or $\nu\left(\right.$ in $\left.\mathrm{cm}^{-1}\right)=10^{4} / \lambda$ (in $\left.\mu \mathrm{m}\right)$. Wavenumbers have the advantage of being directly proportional to energy. As instruments are now available that record linearly either in wavelength or wavenumber, bands will be expressed in both ways in this Monograph. of 2 to $40 \mu \mathrm{m}\left(5000\right.$ to $\left.250 \mathrm{~cm}^{-1}\right)$, discussion of infrared spectra will be confined to this range The range of most interest to the carbohydrate chemist is 2 to $15 \mu \mathrm{m}\left(5000\right.$ to $\left.667 \mathrm{~cm}^{-1}\right)$.

Accurate recordings of spectra may be obtained with a recording, double-beam, infrared spectrophotometer equipped with a prism [e.g., of sodium chloride for the range of 2 to $15 \mu \mathrm{m}$ (5000 to 667 $\left.\mathrm{cm}^{-1}\right)$ ] or a grating. In such instruments, the sample is exposed to infrared radiation, and that radiation passing through the sample is resolved with the prism or grating; the spectrum is then scanned, and the values (bands) at which radiation is absorbed are recorded, providing an infrared absorption spectrogram. For measurement of bands in the region of 2.7 to $3.6 \mu \mathrm{m}$ (3700 to 2780 $\left(\mathrm{cm}^{-1}\right)$, the higher dispersion given by a lithium fluoride prism or a comparable grating is an asset. Instead of a suitable grating, a prisin of potassium bromide may be used for the range of 2 to $25 \mu \mathrm{m}$ (5000 to $400 \mathrm{~cm}^{-1}$ ), and a prism of cesium bromide for 15 to $40 \mu \mathrm{m}\left(667\right.$ to $\left.250 \mathrm{~cm}^{-1}\right)$.

For rapid, routine recording of useful but less accurate spectra, smaller (and cheaper) prism instruments are available as an analytical tool. In the range of 10 to $15 \mu \mathrm{m}\left(1000\right.$ to $\left.667 \mathrm{~cm}^{-1}\right)$, 
such an instrument can routinely give wavenumbers accurate to $\pm 2 \mathrm{~cm}^{-1}$. In the range of 2.5 to $10 \mu \mathrm{m}$ (4000 to $1000 \mathrm{~cm}^{-1}$ ), the inaccuracy is increasingly greater with increasing wavenumber; nevertheless, the reproducibility is satisfactory.

\section{Sampling Techniques}

\subsection{Phase}

Fol recording the infrared spectrum, a carbohydrate or derivative may be prepared as (a) a thin layer of an anhydrous syrup mounted between windows that are transparent to the infrared radiation; (b) a mull with a hydrocarbon oil $\left(\mathrm{Nujol}^{4}\right)$ or an appropriate perhalogenated hydrocarbon, mounted in the same way; (c) a pellet made with an alkali-metal halide; or (d) a solution in an organic solvent or water (in a suitable, water-insoluble cell). Recording is usually done with the sample at room temperature, but bands may be sharper at lower temperatures.

The spectrum of a compound may be different for different physical states. For example, in the solid state, polymorphs of a compound, examined in the same way, may show differences in a few features of their spectra. An example is $N$-benzoyl$2,3,4,6$-tetra- $O$-benzoyl- $\beta$-D-glucosylamine; this exists in a form of $\mathrm{mp} 113-115{ }^{\circ} \mathrm{C}$ which, when heated to $117-120^{\circ} \mathrm{C}$ and allowed to crystallize from the melt, gives a form of $\mathrm{mp} 184{ }^{\circ} \mathrm{C}$ having a somewhat different spectrum (Nujol mull). Also, different crystal habits (same mp) of a compound (resulting, for example, from crystallization of samples from different solvents) may give somewhat different spectra, particularly if examined as mulls (where but little pressure is applied). Shifts of up to $20 \mathrm{~cm}^{-1}$ for certain bands have been noted [3] for crystalline and amorphous forms of some carbohydrates. However, in all such instances, samples of each of the forms, measured after dissolution in the same solvent, or as molten material, give identical spectra. The spectra of crystalline materials often show more bands than the same compounds in solution [4].

Band positions may be shifted, or band intensities altered, if the compound forms hydrogen bonds with the solvent. In solution, molecules of a compound may associate through formation of intermolecular hydrogen bonds. If the concentration is below $0.005 M$, intermolecular hydrogenbonding is negligible for solutions in carbon tetrachloride and similar solvents $[5,6]$; this effect has been used in studying intramolecular hydrogen-bonding in model compounds related to sugars [7].

Pelleting of certain free sugars with an alkali halide changes a crystalline sample to an amorphous form [8, 9]. Moreover, some sugars (for example, $\alpha$-D-glucose) may form a complex with

4 Mention of a commercial product in this article does not constitute endorsement by the National Bureau of Standards. traces of sodium bromide or sodium iodide present in pellets of the corresponding potassium halide [9]. If the pelleting halide is not dry [10], or acquires moisture, the sugar may mutarotate or form a hydrate should the pellet be stored [11]. Consequently, such spectra should always be compared with those obtained for a Nujol mull of the compound, or the pellets should not be stored. However, even though examined immediately after preparation of the pellets, eight of 24 aldopyranosides [12] showed interaction with the pelleting halide, and six of 27 free sugars [13] gave spectrograms that were different in Nujol and in potassium iodide.

\subsection{Comparison of Samples}

As a result of recording and comparing the infrared spectra of a large number of organic compounds, it has been found that every compound having a unique structure gives a unique spectrum. Consequently, for an enantiomorphic pair, every detail of whose structure is identical (but in mirror image), the spectra of the solids, in the same polymorphic modification, are identical [3]. The spectra may differ slightly because of polymorphism, but, for the gaseous or liquid (melt, or solution) phases, the spectra are identical.

Also, for a large molecule, a slight change in structure may change the spectrum only slightly. Thus, proceeding up a series of oligosaccharides containing the same anomeric form of the same monosaccharide residue only, the spectra for the tetraose, pentaose, hexaose, etc., become more and more alike [14].

Consequently, with these exceptions, pure compounds can be identified unequivocally by their infrared spectra. For a carbohydrate, the infrared spectrum is usually a much more specific and characteristic property than the ultraviolet spectrum, melting point, boiling point, density, or refractive index. Thus, although the anomers of a sugar or glycoside differ only in the orientation at one carbon atom, their spectra are quite different [14]. Also, the spectrum of the furanoid form of a sugar derivative differs from that of the pyranoid form in the same anomeric modification, as with methyl $\beta$-D-ribofuranoside and $\beta$-D-ribopyranoside [15].

Hence, the simplest use of infrared spectra is for the identification of a compound. The spectrum of a sample to be identified is compared with the spectra of pure compounds of known structure, measured with the same sampling technique. In this use, it is not necessary that the spectra be analyzed for characteristic absorption bands. However, availability of reference spectra [16-20] of related, pure compounds is essential.

Another use is the precise identification of spectra already in the literature, where the compound studied had been inadequately described. For example, in 1950, Kuhn [14] recorded the spectra of 10 of the crystalline sugars, each in a 


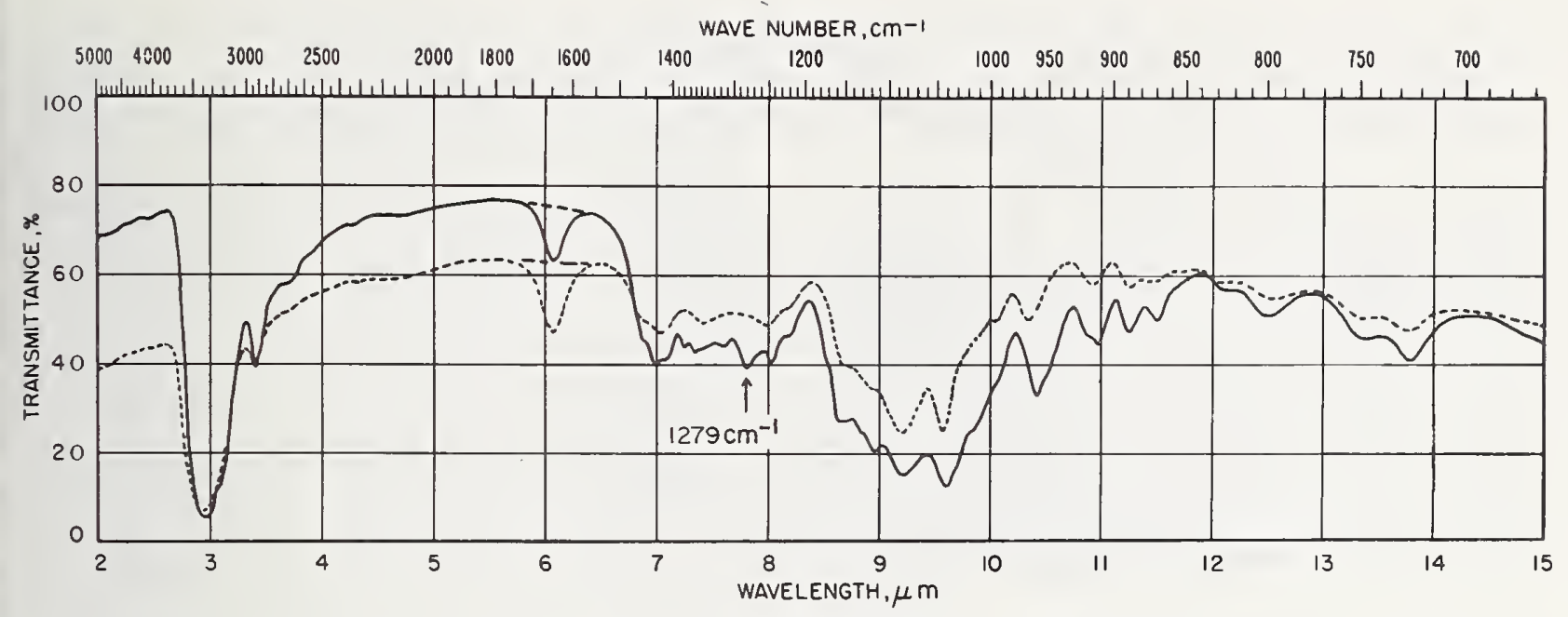

FIGURE 1. Infrared spectra of commercial (- - ) and purified (-) $\beta$-D-ribose [13] in potassium chloride pellets.

[The band at $6.18 \mu \mathrm{m}\left(1618 \mathrm{~cm}^{-1}\right)$ is caused by moisture in the compound, the alkali halide, or both.]

Nujol mull; but, except for one ( $\alpha$-D-glucose), he did not mention which anomer had been employed. Similarly, Urbański et al. [21] recorded the spectra of six sugars, without specifying the anomeric form. These have since been identified [13] by comparison with the spectra of authentic anomeric forms of those sugars.

In another application, infrared spectra can be used for checking the purity of a sample. Commonly, a crude material may show a band that is not present in the spectrum of the pure compound; thus, commercial D-mannitol showed a band at $12.80 \mu \mathrm{m}\left(781 \mathrm{~cm}^{-1}\right)$, due to $\mathrm{D}$-glucitol, removable by recrystallization from aqueous ethanol [22]. In contrast, figure 1 shows the spectrum of pure crystalline $\beta$-D-ribose [13] and that of a commercial specimen. The spectrum of the commercial material does not display a band at $7.82 \mu \mathrm{m}(1279$ $\mathrm{cm}^{-1}$ ) that is present in the spectrum of the pure sugar, presumably because presence of impurity causes poor growth of the crystals, resulting in scattering.

The same figure also serves to illustrate that the spectra may be used in following the isolation or purification of a desired product obtained, for example, by distillation or chromatography. It is not necessary to know what the compound is (nor, initially, to have an infrared spectrum of the pure compound); the concentration or purification procedure can be followed by observing some characteristic infrared band. For example, by recrystallizing $\beta$-D-ribose until the band at 7.82 $\mu \mathrm{m}\left(1279 \mathrm{~cm}^{-1}\right)$ appears and remains of constant intensity, a sample that is "pure" (by infrared spectroscopy) is obtained, without any knowledge of the actual significance of this band. However, the minimum detectable amount of impurity (which may, of course, contribute bands absent from the spectrum of the pure material) varies enormously from one compound to another.

\section{Interpretation of Spectra}

\subsection{General}

A more sophisticated use of infrared spectra permits qualitative analysis for groups of atoms. The motions constantly undergone by the atoms and bonds of a molecule may be examined with a model consisting of springs and balls. A diatomic molecule $\mathrm{A}-\mathrm{B}$ may be represented by two balls, each of a mass proportional to those of atoms A and $\mathrm{B}$, respectively, connected by a spring of strength proportional to the force binding atoms $\mathrm{A}$ and $\mathrm{B}$. Molecule $\mathrm{A}-\mathrm{B}$ can undergo a stretching vibration only along the bond between atoms $A$ and $B$; this vibration occurs in the model if the spring is compressed and then the assemblage is permitted to relax on its own. If the resulting, periodic oscillation is moderate, the system follows Hooke's law approximately, and the frequency (v) of the stretching vibration is given by the equation for simple harmonic vibrations namely $\nu=(f / \mu)^{1 / 2} / 2 \pi c$, where $f$ is the force constant of the bond, $c$ is the velocity of light, and $\mu$ is the reduced mass, defined as $\mu=m_{\mathrm{A}} m_{\mathrm{B}} /\left(m_{\mathrm{A}}+m_{\mathrm{B}}\right)$, where $m_{\mathrm{A}}$ and $m_{\mathrm{B}}$ are the masses of atoms $\mathrm{A}$ and $\mathrm{B}$, respectively. (The equation for $\nu$ applies only to the example considered.)

For a polyatomic molecule, there are many ways in which pairs of atoms may bend, rock, twist, or vibrate, relative to each other and to other pairs, or larger groups, of atoms. Although a mathematical treatment of the infrared spectrum of any pure compound could provide information on the structure through checking of consistency with possible models, the degree of difficulty of such a calculation is a function of the number of atoms and of the symmetry of their geometrical arrangement. Thus, for most sugars, such a treatment would be very difficult, particularly in 


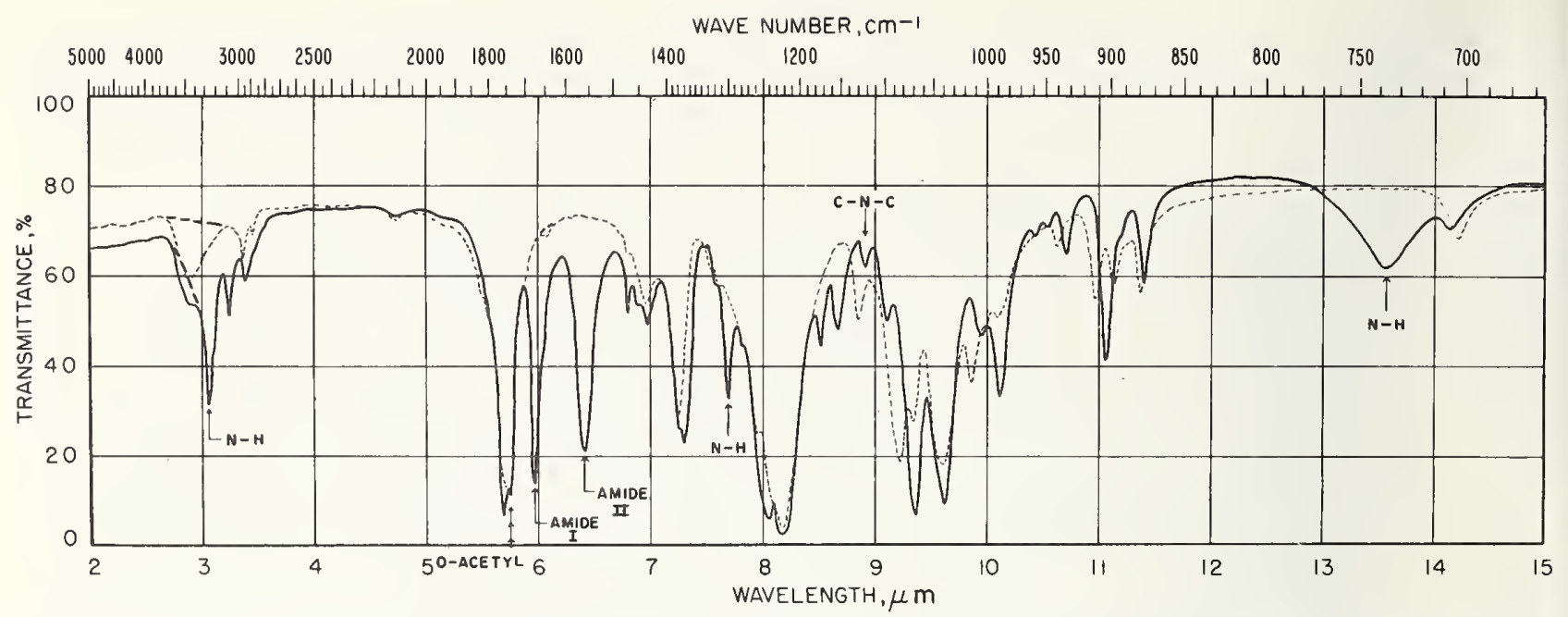

FIGURE 2. Infrared spectra of 1,2,3,4-tetra-O-acetyl- $\beta$-D-xylopyranose $\left(-{ }_{-}\right)$and of $\mathrm{N}$-acetyl-2,3,4-tri-O-acetyl- $\beta$-Dxylopyranosylamine (-) in potassium chloride pellets.

(From Refs. [19] and [20].)

view of additional complications introduced by study of condensed phases.

Consequently, in attempting to correlate the structure of the molecule with the frequencies observed in its infrared spectrum, use has been made of the empirical approach. The method is based on the assumption (not necessarily justified) that the vibrations of a certain group are fairly independent of the rest of the molecule. Then, the spectra (recorded under like conditions) of a large number of compounds having this group are examined, to find out which bands the spectra have in common. For example, the spectra of 24 acetylated glycosides were studied [18], together with those for $21^{\circ}$ nonacetylated glycosides [12]. It was then obvious that (1) all of the acetates showed a band at 5.64 to $5.76 \mu \mathrm{m}$ (1773 to 1736 $\mathrm{cm}^{-1} ; \mathrm{C}=\mathrm{O}$ stretching frequency) not shown by any of the nonacetylated compounds; and (2) all of the nonacetylated glycosides, but not the acetates, showed a band at 2.93 to $3.05 \mu \mathrm{m}$ (3413 to $3279 \mathrm{~cm}^{-1} ;-\mathrm{O}-\mathrm{H}$ stretching). Furthermore, all of the hydrates (but no anhydrous compounds) showed a band at 6.01 to $6.12 \mu \mathrm{m}$ (1664 to 1634 $\mathrm{cm}^{-1}$ ). Here, attention was paid only to the positions of absorption bands, regardless of their relative intensities.

In figure 2 are shown the spectra of $1,2,3,4-$ tetra- $O$-acetyl- $\beta$-D-xylopyranose (1) $[20]$ and of $N$-acetyl-2,3,4-tri- $O$-acetyl- $\beta$-D-xylopyranosylamine (2) [19], compounds that differ by only one connecting atom. In compound 1, C-1 bears an oxygen atom to which is attached an acetyl group, whereas $\mathrm{C}-1$ of compound 2 bears a nitrogen atom to which is attached a hydrogen atom and an acetyl group. Some differences in the spectra are indicated in figure 2, and are discussed in section 4 .

It has been found that, in the absence of disturbing effects, all compounds containing the
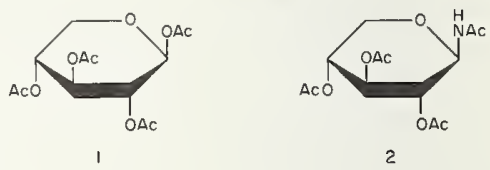

same group will absorb infrared radiation at almost the same wavelength. Thus, bands that occur in the region from 2.0 to $c a .7 \mu \mathrm{m}$ (5000 to ca. $1430 \mathrm{~cm}^{-1}$ ) are usually characteristic groupfrequencies; for these, the associated vibration is well localized, as in $\mathrm{C}=\mathrm{O}$ and $\mathrm{X}-\mathrm{H}$ stretching vibrations. The precise positions of such bands are more reliable for determining the presence of groups than are bands in the region of 7 to 15 $\mu \mathrm{m}\left(1430\right.$ to $\left.667 \mathrm{~cm}^{-1}\right)$. The latter interval, or the interval from 7 to $11 \mu \mathrm{m}$ (1430 to $\left.910 \mathrm{~cm}^{-1}\right)$, is commonly referred to as the "fingerprint region," because it is usually rich in bands that collectively provide a pattern of bands characteristic of the compound; however, the origin of the bands in the fingerprint region is of ten not readily determined, and so a detailed study of this part of the spectrum is generally deferred until the rest of the spectrum has been examined. Bands in the region of 7 to $15 \mu \mathrm{m}$ (1430 to 667 $\mathrm{cm}^{-1}$ ) may arise from single-bond, skeletal stretching-vibrations (between atoms of similar, or the same, mass) or from bending vibrations. The latter occur in this region because less energy is required to produce them; certain of these bands have diagnostic value for groups, but most of them are greatly influenced by structural changes in the molecule. For carbohydrates and their derivatives, the region of 8 to $10 \mu \mathrm{m}$ (1250 to $1000 \mathrm{~cm}^{-1}$ ) contains bands for $-\mathrm{C}-\mathrm{O}-\mathrm{-}$ of esters, ethers, and hydroxyl groups, and may not show highly individual bands for such structures. 
Some group absorptions may be quite different in intensity from one compound to another, even though the wavelength of the absorption is about the same. However, for small molecules, the bands for carbonyl groups are nearly always very strong. If a spectrum has only a weak band in the region of $5.88 \mu \mathrm{m}\left(1700 \mathrm{~cm}^{-1}\right)$, (a) this band is probably not due to carbonyl, (b) the molecule is probably very large and has, perhaps, only one carbonyl group, or (c) a carbonyl compound is possibly present as an impurity. Because of the possibility of interference by other absorptions, the presence of a band at a position expected for a certain group is not conclusive evidence that that group is present in the compound. However, provided that effects (such as hydrogen bonding) that could shift or even remove the band are not operative, the absence of a group absorption usually indicates absence of that group from the sample.

\subsection{Functional Groups in Carbohydrates and Their Derivatives}

Except when electrical (hydrogen bonding, ionization, etc.) or steric effects are operative, every organic compound that possesses a particular group will show the corresponding, characteristic group-frequency in its spectrum, and many compilations of such group-frequencies are available [1]. Table 1 lists the group frequencies in which the sugar chemist is likely to be interested, and provides an estimate of their relative intensities; about half of the characteristic groupfrequencies lie in the range of 2 to $7 \mu \mathrm{m}$ (5000 to $1430 \mathrm{~cm}^{-1}$ ) and the rest above $7 \mu \mathrm{m}$ (below $\left.1430 \mathrm{~cm}^{-1}\right)$.

TABLE 1. Characteristic infrared bands shown by various groups

\begin{tabular}{|c|c|c|c|c|c|}
\hline \multicolumn{2}{|c|}{ Range } & \multirow{2}{*}{ Intensity a } & \multirow{2}{*}{ Group } & \multirow{2}{*}{$\begin{array}{l}\text { Type of } \\
\text { vibration } b\end{array}$} & \multirow{2}{*}{ Remarks } \\
\hline$\mu \mathrm{m}$ & $\mathrm{cm}^{-1}$ & & & & \\
\hline $2.22-2.38$ & $4505-4200$ & $w$ & $\mathrm{C}-\mathrm{H}$ & str. & aliphatic (combination) \\
\hline $2.35-2.50$ & $4255-4000$ & $w$ & $\mathrm{C}-\mathrm{H}$ & str. & aromatic (combination) \\
\hline $2.74-2.86$ & $3650-3500$ & var & $\mathrm{O}-\mathrm{H}$ & str. & free $\mathrm{OH}$, oxime \\
\hline $2.75-2.76$ & $3640-3623$ & $\mathrm{~m}(\mathrm{sharp})$ & $\mathrm{O}-\mathrm{H}$ & str. & free $\mathrm{OH}$, alcohols \\
\hline $2.78-3.23$ & $3600-3100$ & $\mathrm{~m}$ & $\mathrm{O}-\mathrm{H}$ & str. & water of crystallization \\
\hline $2.79-2.92$ & $3590-3425$ & $\operatorname{var}($ sharp $)$ & $\mathrm{O}-\mathrm{H}$ & str. & intramolec. bonded $\mathrm{OH}$ \\
\hline $2.82-2.86$ & $3550-3500$ & & $\mathrm{O}-\mathrm{H}$ & str. & $\begin{array}{l}\text { free } \mathrm{OH} \text {, carboxylic acid (v. dil. } \\
\text { soln.) }\end{array}$ \\
\hline $2.82-2.90$ & $3550-3450$ & $\operatorname{var}($ sharp) & $\mathrm{O}-\mathrm{H}$ & str. & intermolec. bonded $\mathrm{OH}$ (dimeric) \\
\hline $2.82-3.13$ & $3550-3195$ & W & $\mathrm{C}=\mathrm{O}$ & str. & carbonyl (first overtone) \\
\hline$\sim 2.84$ & $\sim 3520$ & s & $\mathrm{N}-\mathrm{H}$ & str. & primary amide (free) \\
\hline$\sim 2.86$ & $\sim 3500$ & $\mathrm{~m}$ & $\mathrm{~N}-\mathrm{H}$ & str. (asym.) & primary amine, free $\mathrm{NH}$ (dil. soln.) \\
\hline $2.86-3.03$ & $3500-3300$ & $\mathrm{~m}$ & $\mathrm{~N}-\mathrm{H}$ & str. & secondary amine, free $\mathrm{NH}$ \\
\hline $2.86-3.27$ & $3500-3060$ & $\mathrm{~m}$ & $\mathrm{~N}-\mathrm{H}$ & str. & associated $\mathrm{NH}$, amine or amide \\
\hline$\sim 2.94$ & $\sim 3400$ & $s$ & $\mathrm{~N}-\mathrm{H}$ & str. & primary amide (free) \\
\hline$\sim 2.94$ & $\sim 3400$ & & $\mathrm{~N}-\mathrm{H}$ & str. (sym.) & primary a mine, free $\mathrm{NH}$ (dil. soln.) \\
\hline $2.94-3.10$ & $3400-3225$ & s(broad) & $\mathrm{O}-\mathrm{H}$ & str. & intermolec. bonded $\mathrm{OH}$ (polymeric) \\
\hline$\sim 2.96$ & $\sim 3380$ & $\mathrm{~m}$ & $\mathrm{NH}_{3}+$ & str. & amine salt (soln.) \\
\hline $2.98-3.18$ & $3355-3145$ & $\mathrm{~m}$ & $\mathrm{NH}_{3}^{+}$ & str. & amine salt (solid); several bands \\
\hline$\sim 2.99$ & $\sim 3350$ & $\mathrm{~m}$ & $\mathrm{~N}-\mathrm{H}$ & str. & primary amide (bonded) \\
\hline$\sim 3.03$ & $\sim 3300$ & & $\mathrm{C}-\mathrm{H}$ & str. & $\equiv \mathrm{C}-\mathrm{H}$, acetylenes \\
\hline $3.03-4.00$ & $3300-2500$ & w(v broad $)$ & $\mathrm{O}-\mathrm{H}$ & str. & H-bonded carboxylic acid dimers \\
\hline$\sim 3.05$ & $\sim 3280$ & & $\mathrm{NH}_{3}+$ & str. & amine salt (soln.) \\
\hline$\sim 3.15$ & $\sim 3175$ & $\mathrm{~m}$ & $\mathrm{~N}-\mathrm{H}$ & str. & primary amide (bonded) \\
\hline $\begin{array}{l}3.17-3.28 \\
3.23-3.25\end{array}$ & $\begin{array}{l}3155-3050 \\
3095-3075\end{array}$ & $w$ & $\stackrel{\mathrm{C}-\mathrm{H}}{\mathrm{C}-\mathrm{H}}$ & str. & $-\mathrm{CH}=\mathrm{C}-\mathrm{O}-$ and $-\mathrm{C}=\mathrm{CH}-\mathrm{O}-$ \\
\hline $3.25-3.30$ & $3075-3030$ & $w-m$ & $\mathrm{C}-\mathrm{H}$ & str. & $\mathrm{C}-\mathrm{H}$ of aromatic ring \\
\hline $3.28-3.34$ & $3050-2995$ & w & $\mathrm{C}-\mathrm{H}$ & str. & $\begin{array}{l}\text { of epoxide (shifts to } 3040-3030 \text { if } \\
\text { ring strain increases) }\end{array}$ \\
\hline $3.29-3.32$ & $3040-3010$ & $\mathrm{~s} ; \mathrm{m}$ & $\mathrm{C}-\mathrm{H}$ & str. & $\begin{array}{l}\geq \mathrm{C}-\mathrm{H} ; \mathrm{RCH}=\mathrm{CH}_{2}, \mathrm{RCH}=\mathrm{CHR}^{\prime} \\
\text { olefin } \text { or trans), } \mathrm{RCR}^{\prime}=\mathrm{CH} \mathrm{R}^{\prime \prime},\end{array}$ \\
\hline$\sim 3.38$ & $\sim 2960$ & s & $\mathrm{C}-\mathrm{H}$ & str. (asym.) & $C$-methyl \\
\hline$\sim 3.42$ & $\sim 2925$ & $\mathrm{~s}$ & $\mathrm{C}-\mathrm{H}$ & str. (asym.) & $>\mathrm{CH}_{2}$, methylene, $\mathrm{Ar}-\mathrm{CH}_{3}$ \\
\hline $3.45-3.47$ & $2900-2880$ & w & $\mathrm{C}-\mathrm{H}$ & str. & $\mathrm{C}-\mathrm{H}$, methine \\
\hline $3.45-3.70$ & $\begin{array}{l}2900-2705 \\
(\text { two })\end{array}$ & $w$ & $\mathrm{C}-\mathrm{H}$ & str. & $-\mathrm{C}(=\mathrm{O}) \mathrm{H}$, aldehyde \\
\hline $3.45-4.35$ & $\begin{array}{l}2900-2300 \\
\text { (several) }\end{array}$ & w & $\mathrm{N}-\mathrm{H}$ & str. & quarternary amine salt, bonded \\
\hline$\sim 3.48$ & $\sim 2875$ & $\mathrm{~s}$ & $\mathrm{C}-\mathrm{H}$ & str. (sym.) & $C$-methyl \\
\hline $\begin{array}{l}\sim 3.51 \\
3.53-3.55\end{array}$ & $\begin{array}{l}\sim 2850 \\
2835-2815\end{array}$ & $\mathrm{~s}$ & $\begin{array}{l}\mathrm{C}-\mathrm{H} \\
\mathrm{C}-\mathrm{H}\end{array}$ & str. (sym.) & $>\mathrm{CH}_{2}$, methylene \\
\hline
\end{tabular}


TABLE 1. Characteristic infrared bands shown by various groups-Continued

\begin{tabular}{|c|c|c|c|c|c|}
\hline \multicolumn{2}{|c|}{ Range } & \multirow{2}{*}{ Intensity a } & \multirow{2}{*}{ Group } & \multirow{2}{*}{$\begin{array}{c}\text { Type of } \\
\text { vibration }\end{array}$} & \multirow{2}{*}{ Remarks } \\
\hline$\mu \mathrm{m}$ & $\mathrm{cm}^{-1}$ & & & & \\
\hline & & & & & $\mathrm{OCH}_{2}-$ \\
\hline$\sim 3.54$ & $\sim 2825$ & $\mathrm{~m}$ & $\mathrm{C}-\mathrm{H}$ & str. & , alkyl acetal \\
\hline$\sim 3.60$ & $\sim 2780$ & & $\mathrm{C}-\mathrm{H}$ & str. & $-\mathrm{O}-\mathrm{OCH}_{2}-\mathrm{CH}_{2}-\mathrm{O}-$ \\
\hline $3.70-3.91$ & $2705-2560$ & $w($ broad $)$ & $\mathrm{P}-\mathrm{OH}$ & str. & phosphoric ester, H-bonded \\
\hline $3.70-4.35$ & $2705-2300$ & $\mathrm{~s}$ & $\mathrm{NH}_{2}{ }^{+}, \mathrm{NH}^{+}$ & str. & (may be several bands) \\
\hline$\sim 3.88$ & $\sim 2580$ & $\mathrm{w}$ & $\mathrm{S}-\mathrm{H}$ & str. & thiol, free \\
\hline$\sim 4.17$ & $\sim 2400$ & w & $\mathrm{S}-\mathrm{H}$ & str. & thiol, H-bonded \\
\hline$\underset{4.42-4.46}{4.4}$ & $\sim 2270$ & vs & $\mathrm{N}=\mathrm{C}=\mathrm{O}$ & asym. str. & isocyanate \\
\hline $\begin{array}{l}4.42-4.46 \\
4.42-4.57\end{array}$ & $2260-2240$ & w & $-\mathrm{C} \equiv \mathrm{N}$ & str. & satd. nitrile \\
\hline $\begin{array}{l}4.42-4.57 \\
4.48-4.51\end{array}$ & $2260-2190$ & var & $\mathrm{C} \equiv \mathrm{C}$ & & $\mathrm{RC} \equiv \mathrm{CR}^{\prime} ;$ acetylenes \\
\hline $4.48-4.51$ & $2230-2215$ & $\mathrm{~s}$ & $-\mathrm{C} \equiv \mathrm{N}$ & str. & unsatd. conj. nitrile \\
\hline $4.55-4.88$ & $2200-2050$ & vs & $\mathrm{C}=\mathrm{S}$ & asym. str. & $\begin{array}{l}-\mathrm{N}-\mathrm{C}=\mathrm{S} \text {, isothiocyanate ( } 2 \text { or } \\
\text { more bands) }\end{array}$ \\
\hline $4.55-5.00$ & $2200-2000$ & $\mathrm{~s}$ & & & $\underset{+}{\text { cyanide, thiocyanate, cyanate }}$ \\
\hline $4.59-4.72$ & $2180-2120$ & & $\mathrm{C} \equiv \mathrm{N}$ & str. & $\mathrm{R}-\mathrm{N} \equiv \mathrm{C}$ \\
\hline $4.63-4.72$ & $2160-2120$ & $\mathrm{~s}$ & $\mathrm{~N} \equiv \mathrm{N}$ & str. & azide \\
\hline $4.67-4.76$ & $2140-2100$ & w & $\mathrm{C} \equiv \mathrm{C}$ & & $\mathrm{RC} \equiv \mathrm{C}-\mathrm{H}$; acetylenes \\
\hline$\sim 5.53$ & $\sim 1810$ & s & $\mathrm{C}=\mathrm{O}$ & str. & - $\mathrm{COCl}$, aliphatic acid chloride \\
\hline $5.62-5.75$ & $1780-1740$ & s & $\mathrm{C}=\mathrm{O}$ & str. & $-\mathrm{O}-(\mathrm{C}=\mathrm{O})-\mathrm{O}-$, cärbonate \\
\hline $\begin{array}{l}\sim 5.65 \\
5.73-5.76\end{array}$ & $\sim 1770$ & $\mathbf{s}$ & $\mathrm{C}=\mathrm{O}$ & str. & $\gamma$-lactone \\
\hline & $1745-1735$ & $\mathrm{~s}$ & $\mathrm{C}=\mathrm{O}$ & str. & satd. esters \\
\hline $5.75-5.81$ & $\widetilde{1740-1720}$ & $\begin{array}{l}\mathrm{S} \\
\mathrm{s}\end{array}$ & $\begin{array}{l}\mathrm{C}=\mathrm{O} \\
\mathrm{C}=\mathrm{O}\end{array}$ & $\begin{array}{l}\text { str. } \\
\text { str. }\end{array}$ & $\begin{array}{l}\delta \text {-lactone } \\
-\mathrm{C}(=\mathrm{O}) \mathrm{H}, \text { aldehyde }\end{array}$ \\
\hline$\sim 5.80$ & $\sim 1725$ & $\mathrm{~s}$ & $\mathrm{C}=\mathrm{O}$ & str. & formic ester \\
\hline $5.80-5.87$ & $1725-1705$ & $\mathrm{~s}$ & $\mathrm{C}=\mathrm{O}$ & str. & ketone \\
\hline$\sim 5.81$ & $\sim 1720$ & $\mathrm{~s}$ & $\mathrm{C}=\mathrm{O}$ & str. & benzoic ester \\
\hline $5.81-5.88$ & $1720-1700$ & $\mathrm{~s}$ & $\mathrm{C}=\mathrm{O}$ & str. & $\begin{array}{l}\text { - } \mathrm{COOH} \text {; aliphatic carboxylic acid } \\
\text { (dimer) }\end{array}$ \\
\hline $5.88-5.99$ & $1700-1670$ & $\mathrm{~s}$ & $\mathrm{C}=\mathrm{O}$ & str. & $\begin{array}{l}\text { - CONHR, secondary amide, free } \\
\text { (dil. soln.): Amide I }\end{array}$ \\
\hline $5.92-5.99$ & $1690-1670$ & $\mathrm{~s}$ & $\mathrm{C}=\mathrm{O}$ & str. & $\begin{array}{l}\text { - } \mathrm{CONH}_{2} \text {, primary amide, free } \\
\text { (dil. soln.): Amide I }\end{array}$ \\
\hline $5.95-6.14$ & $1680-1630$ & $\mathrm{~s}$ & $\mathrm{C}=\mathrm{O}$ & str. & secondary amide (solid) \\
\hline $5.95-6.17$ & $1680-1620$ & var & $\mathrm{C}=\mathrm{C}$ & str. & nonconjugated $\mathrm{C}=\mathrm{C}$ \\
\hline $5.96-5.99$ & $1678-1668$ & & $\mathrm{C}=\mathrm{C}$ & & trans olefin; $\mathrm{RHC}=\mathrm{CHR}^{\prime}$ \\
\hline$\sim 5.97$ & $\sim 1675$ & $\mathrm{~s}$ & $\mathrm{C}=\mathrm{S}$ & str. & thioester \\
\hline$\sim 5.97$ & $\sim 1675$ & $\mathrm{~s}$ & $\mathrm{C}=\mathrm{O}$ & str. & thioester \\
\hline$\sim 5.99$ & $\sim 1670$ & w & $\mathrm{C}=\mathrm{N}$ & str. & aliphatic oxime \\
\hline $5.99-6.17$ & $1670-1620$ & $\mathrm{~s}$ & $\mathrm{C}=\mathrm{O}$ & str. & $\begin{array}{l}\text { primary amide (solid), H-bonded, } \\
2 \text { bands: Amide I }\end{array}$ \\
\hline $6.02-6.05$ & $1662-1652$ & & $\mathrm{C}=\mathrm{C}$ & & cis olefin; $\mathrm{RHC} \Longrightarrow \mathrm{CHR}^{\prime}$ \\
\hline $6.03-6.07$ & $1658-1648$ & & $\mathrm{C}=\mathrm{C}$ & & terminal olefin; $\mathrm{RR}^{\prime} \mathrm{C}=\mathrm{CH}_{2}$ \\
\hline $6.06-6.17$ & $1650-1620$ & $\mathrm{~s}$ & $\mathrm{~N}-\mathrm{H}$ & def. & primary amide (solid): Amide II, \\
\hline $6.06-6.25$ & $1650-1600$ & s & $\mathrm{NO}_{2}$ & asym. str. & $-\mathrm{O}-\mathrm{NO}_{2}$, nitrate \\
\hline $6.06-6.33$ & $1650-1580$ & $\mathrm{~m}-\mathrm{s}$ & $\mathrm{N}-\mathrm{H}$ & def. & $\mathrm{NH}_{2} ;$ primary amine \\
\hline $6.06-6.45$ & $1650-1550$ & w & $\mathrm{N}-\mathrm{H}$ & def. & NHR; secondary amine \\
\hline $6.07-6.11$ & $1648-1638$ & & $\mathrm{C}=\mathrm{C}$ & & terminal olefin; $\mathrm{RHC}=\mathrm{CH}_{2}$ \\
\hline$\sim 6.15$ & $\sim 1625$ & $\mathrm{~s}$ & $\mathrm{C}=\mathrm{C}$ & str. & Ph-conjugated $\mathrm{C}=\mathrm{C}$ \\
\hline $6.15-6.31$ & 1625-1585 & $\mathrm{m}$ & $\mathrm{C}=\mathrm{C}$ & $\begin{array}{l}\text { skeletal, in- } \\
\text { plane }\end{array}$ & aromatic $\mathrm{C}=\mathrm{C}$ \\
\hline $6.17-6.29$ & $1620-1590$ & s & $\mathrm{N}-\mathrm{H}$ & def. & primary amide (dil. soln.) \\
\hline $6.17-6.41$ & $1620-1560$ & $\mathrm{~m}-\mathrm{s}$ & $\mathrm{NH}_{2}{ }^{+}$ & def. & \\
\hline $6.21-6.49$ & $1610-1540$ & vs & $\mathrm{C}-\mathrm{O}$ & asym. str. & $-\mathrm{COO}^{-}$, carboxylate \\
\hline$\sim 6.25$ & $\sim 1600$ & $\mathrm{~s}$ & $\mathrm{C}=\mathrm{C}$ & str. & $\mathrm{CO}$ or $\mathrm{C}=\mathrm{C}$ conjugated with $\mathrm{C}=\mathrm{C}$ \\
\hline$\sim 6.31$ & $\sim 1585$ & $\mathrm{~m}$ & $\mathrm{NH}_{3}+$ & asym. def. & amine salt \\
\hline $6.33-6.58$ & $1580-1520$ & $\mathrm{~m}$ & $\mathrm{C}=\mathrm{N}$ (plus & & pyrimidines \\
\hline $6.37-6.60$ & $1570-1515$ & s & $\mathrm{N}-\mathrm{H}$ & def. & secondary amide (solid) : Amide II \\
\hline $6.45-6.62$ & $1550-1510$ & $\mathrm{~s}$ & $\mathrm{~N}-\mathrm{H}$ & def. & secondary amide (dil. soln.) \\
\hline$\sim 6.67$ & $\sim 1500$ & var & $\mathrm{C}=\mathrm{C}$ & $\begin{array}{l}\text { skeletal, in- } \\
\text { plane }\end{array}$ & aromatic $\mathrm{C}=\mathrm{C}$ \\
\hline $6.67-6.80$ & $1500-1470$ & $\mathrm{~s}$ & $\mathrm{C}=\mathrm{S}$ & str. & $-\mathrm{N}-\mathrm{C}=\mathrm{S}$ \\
\hline $6.67-7.69$ & $1500-1300$ & $\mathrm{~m}$ & $\mathrm{NH}_{3}+$ & sym. def. & amine salt \\
\hline$\sim 6.81$ & $\sim 1468$ & $\mathbf{s}$ & $\mathrm{C}-\mathrm{H}$ & scissoring & alkane $-\mathrm{CH}_{2}-$ \\
\hline$\sim 6.85$ & $\sim 1460$ & $\mathrm{~m}$ & $\mathrm{C}-\mathrm{H}$ & bend (asym.) & $-\mathrm{CH}_{3}$ \\
\hline
\end{tabular}


TABLE 1. Characteristic infrared bands shown by various groups-Continued




TABLE 1. Characteristic infrared bands shown by various groups-Continued

\begin{tabular}{|c|c|c|c|c|c|}
\hline \multicolumn{2}{|c|}{ Range } & \multirow{2}{*}{ Intensity } & \multirow{2}{*}{ Group } & \multirow{2}{*}{$\begin{array}{c}\text { Type of } \\
\text { vibration }\end{array}$} & \multirow{2}{*}{ Remarks } \\
\hline$\mu \mathrm{m}$ & $\mathrm{cm}^{-1}$ & & & & \\
\hline $10.53-12.35$ & $950-810$ & & $\mathrm{C}-\mathrm{O}$ & str. & epoxide \\
\hline$\sim 10.55$ & $\sim 948$ & s & $\mathrm{C}-\mathrm{H}$ & bend & vinyl ester \\
\hline$\sim 10.81$ & $\sim 925$ & & $\mathrm{C}-\mathrm{O}$ & str. & methylene acetal \\
\hline $11.17-11.30$ & $895-885$ & & $\mathrm{C}-\mathrm{H}$ & $\begin{array}{l}\text { out-of-plane } \\
\text { bend }\end{array}$ & $\mathrm{RR}^{\prime} \mathrm{C}=\mathrm{CH}_{2}$ \\
\hline$\sim 11.90$ & $\sim 840$ & vs & $\mathrm{Si}-\mathrm{CH}_{3}$ & str. & $\mathrm{Si}\left(\mathrm{CH}_{3}\right)_{3}$, trimethylsilyl \\
\hline $11.90-12.66$ & $840-790$ & & $\mathrm{C}-\mathrm{H}$ & $\begin{array}{l}\text { out-of-plane } \\
\text { bend }\end{array}$ & $\mathrm{R} \mathrm{R}^{\prime} \mathrm{C}=\mathrm{CHR} \mathrm{R}^{\prime \prime}$ \\
\hline $11.90-12.66$ & $840-790$ & m & $\mathrm{C}-\mathrm{H}$ & skeletal & $\left(\mathrm{CH}_{3}\right)_{2} \mathrm{C}<$, isopropyl \\
\hline $11.90-13.33$ & $840-750$ & & $\mathrm{C}-\mathrm{O}$ & str. & epoxide \\
\hline $12.00-12.35$ & $833-810$ & vs & $\mathrm{C}-\mathrm{H}$ & $\begin{array}{l}\text { out-of-plane } \\
\text { bend }\end{array}$ & $p$-substituted phenyl \\
\hline$\sim 12.50$ & $\sim 800$ & $w$ & $\mathrm{NH}_{3}+$ & rocking & amine salt \\
\hline$\sim 12.50$ & $\sim 800$ & $w$ & $\mathrm{NH}_{2}^{+}$ & rocking & \\
\hline $\begin{array}{c}12.99-13.70 \\
14.08-14.49\end{array}$ & $\begin{array}{c}770-730 \\
710-690\end{array}$ & s & $\mathrm{C}-\mathrm{H}$ & $\begin{array}{l}\text { out-of-plane } \\
\text { bend }\end{array}$ & unsubstituted phenyl \\
\hline$\sim 13.25$ & $\sim 755$ & vs & $\mathrm{Si}-\mathrm{CH}_{3}$ & str. & $\mathrm{Si}\left(\mathrm{CH}_{3}\right)_{3}$, trimethylsilyl \\
\hline $13.33-14.08$ & $750-700$ & s & $\mathrm{C}-\mathrm{Cl}$ & str. & monochloro derivs. \\
\hline$\sim 13.89$ & $\sim 720$ & $\mathrm{~m}$ (broad) & $\mathrm{N}-\mathrm{H}$ & def. & secondary amide, bonded: Amide $V$ \\
\hline $14.18-17.54$ & $705-570$ & $\mathbf{w}$ & $\mathrm{C}-\mathrm{S}$ & str. & thiol, sulfide \\
\hline$\sim 14.49$ & $\sim 690$ & & $\mathrm{C}-\mathrm{H}$ & $\begin{array}{l}\text { out-of-plane } \\
\text { bend }\end{array}$ & cis $\mathrm{RHC}=\mathrm{CHR}^{\prime}$ \\
\hline$\sim 15.39$ & $\sim 650$ & $\mathrm{~s}$ & $\mathrm{C}-\mathrm{Br}$ & str. & bromo derivs. \\
\hline $16.67-20.83$ & $600-480$ & $\mathrm{~s}$ & $\mathrm{C}-\mathrm{I}$ & str. & iodo derivs. \\
\hline $18.19-22.22$ & $550-450$ & vw & $S-S$ & str. & disulfide \\
\hline
\end{tabular}

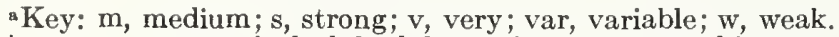

basym., asymmetrical; def., deformation; str., stretching; sym., symmetrical.

Description of a group vibration as $A-B$ stretching or $\mathrm{A}-\mathrm{B}-\mathrm{C}$ bending is, at best, a first approximation. All of the bonds in a group are usually changing to some extent during a vibration. One bond may dominate, and it is then reasonable to describe the vibration as the motion of that bond, but this is by no means always justifiable. Thus, for the amide group vibrations, the stretching motions of $\mathrm{C}=\mathrm{O}, \mathrm{C}-\mathrm{N}$, and $\mathrm{N}-\mathrm{H}$ and the corresponding bending motions are often highly mixed; consequently, the amide group vibrations are described as Amide I, II, III, and so on.

In the following discussion of some of the more important bands, all values for their positions are approximate unless a range is stated; even so, although frequencies generally fall within the limits indicated, they may, in special cases, lie beyond these ranges. Consequently, when the correlations are used, all other available evidence should also receive consideration. Also, in this discussion, the reference given is usually, but not necessarily, that for the first mention of the correlation for carbohydrates.

\subsection{1. $\mathrm{C}-\mathrm{H}$ Bands}

All sugars and their derivatives possess the methylidyne (methine) grouping $-\mathrm{C}-\mathrm{H}$, char- acterized by a band near $3.45 \mu \mathrm{m}\left(2900 \mathrm{~cm}^{-}\right)^{1}$ assigned to $\mathrm{C}-\mathrm{H}$ stretching. Hence, this band has no diagnostic value for these compounds.

Acetylenic compounds give a strong band for $\mathrm{C}-\mathrm{H}$ stretching of $\equiv \mathrm{C}-\mathrm{H}$ at about $3.07 \mu \mathrm{m}$ $\left(3255 \mathrm{~cm}^{-1}\right)$; this occurs at $3.03 \mu \mathrm{m}\left(3300 \mathrm{~cm}^{-1}\right)$ for 5-hexyne-D-lyxo-1,2,3,4-tetrol tetraacetate [23] and at $3.11 \mu \mathrm{m}\left(3215 \mathrm{~cm}^{-1}\right)$ for 1,2:3,4-di$O$-isopropylidene-6-heptyne-D-gulo- $1,2,3,4,5$-pentol [24]; the L-manno isomer of the latter shows the band at $3.06 \mu \mathrm{m}\left(3268 \mathrm{~cm}^{-1}\right)$.

Other $\mathrm{C}-\mathrm{H}$ stretching frequencies encountered with sugar derivatives are: olefinic $=\mathrm{CH}_{2}$ doublet at $3.25 \mu \mathrm{m}\left(3075 \mathrm{~cm}^{-1}\right)$ and $3.36 \mu \mathrm{m}\left(2975 \mathrm{~cm}^{-1}\right)$; Ar-H at $3.28 \mu \mathrm{m}\left(3050 \mathrm{~cm}^{-1}\right)$; olefinic $=\stackrel{\text { C }}{\mathrm{C}}-\mathrm{H}$ at $3.31 \mu \mathrm{m}\left(3020 \mathrm{~cm}^{-1}\right) ;-\mathrm{CH}_{2}$ - doublet at 3.42 $\mu \mathrm{m}\left(2925 \mathrm{~cm}^{-1}\right)$ and $3.51 \mu \mathrm{m}\left(2850 \mathrm{~cm}^{-1}\right)$; and $C$-methyl doublet at $3.38 \mu \mathrm{m}\left(2960 \mathrm{~cm}^{-1}\right)$ and $3.49 \mu \mathrm{m}\left(2865 \mathrm{~cm}^{-1}\right)$. Thus, a group of 28 cyclic acetals of various sugars all showed [4] a band at 3.32 to $3.37 \mu \mathrm{m}\left(3010\right.$ to $\left.2965 \mathrm{~cm}^{-1}\right)$. As regards $O$-methyl, all of 21 methyl aldopyranosides studied [12] showed a characteristic $\mathrm{C}-\mathrm{H}$ stretching band at $3.47-3.52 \mu \mathrm{m} \quad\left(2882-2841 \mathrm{~cm}^{-1}\right)$, not shown by $C$-methyl or ethoxyl groups [25] ${ }^{\circ}$ that permits detection of the glycosidic methoxyl group.

Some deformation frequencies for $\mathrm{C}-\mathrm{H}$ are: $-\mathrm{CH}_{2}$ - at $6.89 \mu \mathrm{m}\left(1450 \mathrm{~cm}^{-1}\right)$, and $C$-methyl 
at $7.27 \mu \mathrm{m}\left(1375 \mathrm{~cm}^{-1}\right)$. The $C$-methyls of the isopropyl group show bands at 7.25 and 7.30 $\mu \mathrm{m}$ (1380 and $1370 \mathrm{~cm}^{-1}$ ) that are particularly useful for indicating the presence of the isopropylidene acetal structure.

Weak bands for $\mathrm{C}-\mathrm{H}$ in-plane deformations of the unsubstituted phenyl group are found at 8.51 to $8.89 \mu \mathrm{m}$ (1175 to $1125 \mathrm{~cm}^{-1}$ ), 9.01 to $9.35 \mu \mathrm{m}$ (1110 to $\left.1070 \mathrm{~cm}^{-1}\right)$, and 9.35 to $10.00 \mu \mathrm{m}(1070$ to $\left.1000 \mathrm{~cm}^{-1}\right)$; strong bands for $\mathrm{C}-\mathrm{H}$ out-ofplane deformations occur at 12.99 to $13.70 \mu \mathrm{m}$ (770 to $\left.730 \mathrm{~cm}^{-1}\right)$ and 14.08 to $14.49 \mu \mathrm{m}(710$ to $\left.690 \mathrm{~cm}^{-1}\right)$.

For substituted phenyl groups, the bands for $\mathrm{C}-\mathrm{H}$ in-plane and out-of-plane deformation differ according to the position and degree of substitution. For the $p$-substituted phenyl group, most commonly encountered in sugar chemistry, weak bands (in-plane deformations) are found at 8.17 to $8.51 \mu \mathrm{m}$ (1225 to $1175 \mathrm{~cm}^{-1}$ ), 8.89 to 9.17 $\mu \mathrm{m}$ (1125 to $1090 \mathrm{~cm}^{-1}$ ), and 9.35 to $10.00 \mu \mathrm{m}$ (1070 to $1000 \mathrm{~cm}^{-1}$ ), and a strong band (out-ofplane deformation) at 11.63 to $12.50 \mu \mathrm{m}$ (860 to $\left.800 \mathrm{~cm}^{-1}\right)$. Thus, the $p$-substituted phenyl group of $p$-toluenesulfonic esters of alditols [26] and sugars [27] shows a hydrogen out-of-plane deformation at 12.05 to $12.35 \mu \mathrm{m}\left(830\right.$ to $\left.810 \mathrm{~cm}^{-1}\right)$, not shown by methanesulfonates.

For the olefins, $\mathrm{CHR}=\mathrm{CH}_{2}$ shows a weak band at 7.04 to $7.09 \mu \mathrm{m}$ (1420 to $\left.1410 \mathrm{~cm}^{-1}\right)$, a band at 7.69 to $7.75 \mu \mathrm{m}$ (1300 to $1290 \mathrm{~cm}^{-1}$ ), a mediumstrength band at 10.05 and $10.15 \mu \mathrm{m}$ (995 to 985 $\mathrm{cm}^{-1}$, and a strong band at 10.93 to $11.05 \mu \mathrm{m}$ (915 to $905 \mathrm{~cm}^{-1}$ ). A cis double bond shows a weak band at 7.04 to $7.14 \mu \mathrm{m}\left(1420\right.$ to $\left.1400 \mathrm{~cm}^{-1}\right)$ and a strong band at 13.70 to $15.04 \mu \mathrm{m}$ (730 to $665 \mathrm{~cm}^{-1}$ ); a trans double bond shows a weak band at 7.55 to $7.75 \mu \mathrm{m}\left(1325\right.$ to $\left.1290 \mathrm{~cm}^{-1}\right)$ and a strong band at 10.20 to $10.42 \mu \mathrm{m}\left(980\right.$ to $\left.960 \mathrm{~cm}^{-1}\right)$. For example, trans-3-hexene-D-threo-1,2,5,6-tetrol [28] shows bands at 7.55 and $10.25 \mu \mathrm{m}$ (1325 and $\left.976 \mathrm{~cm}^{-1}\right)$; its $1,2: 5,6$-di- $O$-isopropylidene derivative shows bands at $7.65 \mu \mathrm{m}\left(1307 \mathrm{~cm}^{-1}\right)$ and $10.30 \mu \mathrm{m}\left(971 \mathrm{~cm}^{-1}\right)$.

Whiffen et al. [29] have succeeded in identifying the $\mathrm{C}-\mathrm{H}$ deformation vibrations at the anomeria carbon atom of various aldoses by replacing the hydrogen atom on $\mathrm{C}-1$ with deuterium. For example, to prepare $\alpha-\mathrm{D}$-glucopyranose- $1-C-d$, they dissolved $\mathrm{D}$-glucono-1,5-lactone in deuterium oxide, reduced the carbonyl group to $-\mathrm{C}-\mathrm{D}(\mathrm{OD})$ with

sodium amalgam in deuterium oxide, and then converted the $\mathrm{OD}$ groups into $\mathrm{OH}$ groups by 3 times dissolving in water and evaporating; the $\mathrm{C}-\mathrm{D}$ bond at $\mathrm{C}-1$ remained unchanged. The spectrum of the $\alpha$-D-glucopyranose- $1-C-d$ was then compared with that of $\alpha-D$-glucopyranose. Now, by theory, if ${ }^{1} \mathrm{H}$ is replaced by $\mathrm{D}\left({ }^{2} \mathrm{H}\right)$, the ${ }^{1} \mathrm{H}$ deformation frequencies are approximately $\sqrt{2}$ times the corresponding deuterium frequencies (in $\mathrm{cm}^{-1}$ ) if the deformation corresponds to a pure bending or stretching mode. They found $\mathrm{C}-1-\mathrm{H}$ at $7.28 \mu \mathrm{m}\left(1375 \mathrm{~cm}^{-1}\right)$ and $\mathrm{C}-1-\mathrm{D}$ at $9.13 \mu \mathrm{m}\left(1095 \mathrm{~cm}^{-1}\right.$ ) (frequency ratio 1.26$)$; and $\mathrm{C}-1-\mathrm{H}$ at $7.79 \mu \mathrm{m}\left(1284 \mathrm{~cm}^{-1}\right)$ and $\mathrm{C}-1-\mathrm{D}$ at $10.36 \mu \mathrm{m}\left(965 \mathrm{~cm}^{-1}\right)$ (ratio 1.33), as compared to the theoretical ratio of 1.414 . Similar assignments were made for the $\beta$ anomer and for the two anomers of other sugars.

\subsubsection{N-H Bands}

In dilute solution in a nonpolar solvent, primary amines show two bands in the region of 2.86 to $3.03 \mu \mathrm{m}$ (3500 to $3300 \mathrm{~cm}^{-1}$ ) due to stretching vibrations of the $\mathrm{NH}_{2}$ group. If hydrogen bonding occurs, or if the solid is examined, the range is shifted to 2.86 to $3.23 \mu \mathrm{m}$ (3500 to $3100 \mathrm{~cm}^{-1}$ ). Secondary amines in dilute solution show only one $\mathrm{N}-\mathrm{H}$ stretching band, at 2.94 to $3.03 \mu \mathrm{m}$ (3400 to $3300 \mathrm{~cm}^{-1}$ ).

An $\mathrm{N}-\mathrm{H}$ deformation frequency is shown by primary amines at 6.08 to $6.45 \mu \mathrm{m}$ (1645 to 1550 $\mathrm{cm}^{-1}$ ); thus, D-glucosylamine shows a band at $6.17 \mu \mathrm{m}\left(1621 \mathrm{~cm}^{-1}\right)$, and 2-amino-2-deoxy-Dglucopyranose at $6.25 \mu \mathrm{m}\left(1600 \mathrm{~cm}^{-1}\right)$ [3]. A band at 6.33 to $6.62 \mu \mathrm{m}\left(1580\right.$ to $\left.1510 \mathrm{~cm}^{-1}\right)$ is shown by $-\mathrm{NH}-$.

The $\mathrm{NH}_{2}$ deformation frequency of primary amides occurs at 6.06 to $6.17 \mu \mathrm{m}(1650$ to 1620 $\left.\mathrm{cm}^{-1}\right)$ for the solid, and at 6.17 to $6.29 \mu \mathrm{m}(1620$ to $1590 \mathrm{~cm}^{-1}$ ) for solutions; it is called the Amide II band. Secondary amides, having an NH group, show the Amide II band at 6.37 to $6.60 \mu \mathrm{m}$ (1570 to $1515 \mathrm{~cm}^{-1}$ ) for the solid, and at 6.45 to $6.62 \mu \mathrm{m}$ (1550 to $1510 \mathrm{~cm}^{-1}$ ) for solutions. Hydrogen-bonded secondary amides show an NH deformation mode near $13.89 \mu \mathrm{m}\left(720 \mathrm{~cm}^{-1}\right)$, called the Amide $\mathrm{V}$ band.

The spectra of 16 1-acetamido derivatives of sugars [19] showed at least one band at 2.98 to $3.09 \mu \mathrm{m}$ (3356 to $3236 \mathrm{~cm}^{-1}$ ), attributed to $\mathrm{N}-\mathrm{H}$ stretching; and, at 6.35 to $6.49 \mu \mathrm{m}$ (1575 to 1541 $\mathrm{cm}^{-1}$ ), the Amide II band. In a study of the spectra of 60 1-acylamido derivatives of aldofuranoid, aldopyranoid, and acyclic sugars [2], all of the compounds were secondary amides, and all of them showed at least one band at 2.89 to 3.10 $\mu \mathrm{m}$ (3460 to $3226 \mathrm{~cm}^{-1}$ ) due to $\mathrm{N}-\mathrm{H}$ stretching; in this region, completely esterified compounds could not be distinguished from those having free hydroxyl groups that would show $\mathrm{O}-\mathrm{H}$ stretching in the same region. All of the compounds showed a band at 6.35 to $6.65 \mu \mathrm{m}$ (1575 to $1504 \mathrm{~cm}^{-1}$; Amide II).

The acyclic, 1,1-bis(acylamido)-1-deoxyalditols showed [2] two Amide II bands, suggesting that the two acylamido groups on C-1 of these compounds are not equivalent. They may have a hydrogen-bonded structure, possibly of the following type. 


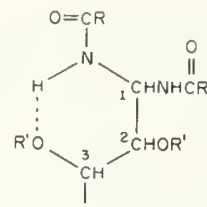

where $\mathrm{R}$ is $\mathrm{Me}, \mathrm{Et}$, or $\mathrm{Ph}$; and $\mathbf{R}^{\prime}$ is $\mathrm{H}, \mathrm{Ac}, \mathrm{EtCO}$, or $\mathrm{Bz}$.

\subsection{3. $\mathrm{O}-\mathrm{H}$ Bands}

Compounds having a free hydroxyl group show a band for $\mathrm{O}-\mathrm{H}$ stretching at 2.68 to $2.84 \mu \mathrm{m}$ (3730 to $3520 \mathrm{~cm}^{-1}$ ). The $\mathrm{O}-\mathrm{H}$ bond is weakened if the hydroxyl group is hydrogen-bonded, and the band is broadened, with a shift to longer wavelength, 2.84 to $3.22 \mu \mathrm{m}$ (3520 to $3100 \mathrm{~cm}^{-1}$ ). The band for $\mathrm{O}-\mathrm{H}$ deformation lies at 9.26 to $9.71 \mu \mathrm{m}$ (1080 to $\left.1030 \mathrm{~cm}^{-1}\right)$. For sugars, differentiation of primary from anomeric and secondary hydroxyl groups by $\mathrm{OH}$ frequencies is not feasible, because of frequency shifts caused by hydrogen bonding.

Infrared spectra may be used for the detection of hydrogen bonding, which may be between one molecule and another (intermolecular) or in one molecule (intramolecular). For compounds soluble in carbon tetrachloride, intermolecular hydrogenbonding is negligible at concentrations below $0.005 M$, and absorptions at $c a .2 .79 \mu \mathrm{m}$ ( $c a$. $\left.3585 \mathrm{~cm}^{-1}\right)$ and $c a .2 .76 \mu \mathrm{m}\left(c a .3625 \mathrm{~cm}^{-1}\right)$ may be associated with bonded and free hydroxyl groups, respectively [5]. In this way, the extent of intramolecular hydrogen bonding may be determined [7, 30]. In pyranoid (and $m$ - or $p$ dioxane) derivatives, a suitably located hydroxyl group can form a hydrogen bond with the ring oxygen-atom, as shown in figure 3 . The spectra are consistent with the equilibria shown, assuming that the molecules exist preferentially in the chair

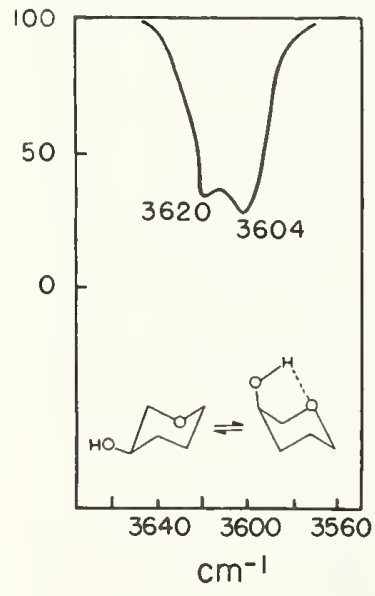

A

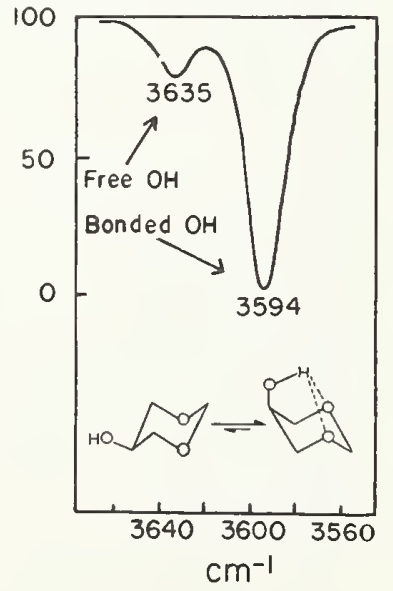

B
Figure 3. Infrared spectric of tetrahydropyran-3-ol $(A)$ and of 1,3-O-methyleneglycerol $(B)$ in carbon tetrachloride; both solutions $0.005 \mathrm{M}$.

(From Ref. [7].) conformations (as against non-chair conformations). For compounds that are insufficiently soluble in carbon tetrachloride, Akermark [31] has suggested the use of $p$-dioxane, which disrupts intermolecular hydrogen-bonds but does not affect strong intramolecular hydrogen-bonds.

In solution, both penta-O-acetyl-aldehydo-Dgalactose aldehydrol and the corresponding ethyl hemiacetal show [17] a band at $2.78 \mu \mathrm{m}$ (3597 $\left.\mathrm{cm}^{-1}\right)$ for free hydroxyl, and a band at $2.87 \mu \mathrm{m}$ $\left(3483 \mathrm{~cm}^{-1}\right)$ for hydrogen-bonded hydroxyl.
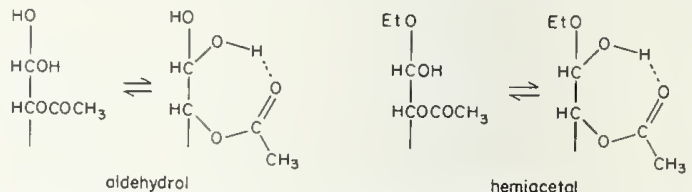

The OD bands in the spectra of fully 0 -deuterated sugars have been examined [32]. The $\mathrm{OH}$ band at $2.95 \mu \mathrm{m}\left(3390 \mathrm{~cm}^{-1}\right)$ of $\alpha, \beta$-D-glucose was shifted, by deuteration, to $4.05 \mu \mathrm{m}\left(2469 \mathrm{~cm}^{-1}\right)$, a wavenumber ratio of 1.37 , and other new bands appeared.

\subsection{4. $\mathrm{C} \equiv \mathrm{C}$ and $\mathrm{C}=\mathrm{C}$ Bands}

The $\mathrm{C} \equiv \mathrm{C}$ stretching absorption is weak and has limited diagnostic value; it is not shown by symmetrically disubstituted acetylenes. A weak stretching band for $\mathrm{H}-\mathrm{C} \equiv \mathrm{C}-\mathrm{R}$ lies at 4.65 to $4.76 \mu \mathrm{m} \mathrm{(2150} \mathrm{to} 2100 \mathrm{~cm}^{-1}$ ); thus, 5-hexyne-Dlyxo-1,2,3,4-tetrol tetraacetate shows [23] a band at $4.65 \mu \mathrm{m}\left(2150 \mathrm{~cm}^{-1}\right)$ and two 6-heptynepentol derivatives show [24] the band at 4.72 to $4.74 \mu \mathrm{m}$ (2120 to $2110 \mathrm{~cm}^{-1}$ ). For $\mathrm{R}-\mathrm{C} \equiv \mathrm{C}-\mathrm{R}^{\prime}$, the band is at 4.42 to $4.57 \mu \mathrm{m}\left(2260\right.$ to $\left.2190 \mathrm{~cm}^{-1}\right)$.

Stretching frequencies for (phenyl) conjugated $\mathrm{C}=\mathrm{C}$ bonds give a strong band at about $6.15 \mu \mathrm{m}$ $\left(1625 \mathrm{~cm}^{-1}\right)$; for $\mathrm{CO}$ or $\mathrm{C}=\mathrm{C}$ conjugation, the band occurs at about $6.25 \mu \mathrm{m}\left(1600 \mathrm{~cm}^{-1}\right)$. Bands for nonconjugated $\mathrm{C}=\mathrm{C}$ bonds occur at 5.95 to $6.17 \mu \mathrm{m}$ (1680 to $\left.1620 \mathrm{~cm}^{-1}\right)$. For olefins, bands are found for a cis double bond in $\mathrm{RCH}=\mathrm{CHR}^{\prime}$ at 6.02 to $6.05 \mu \mathrm{m}\left(1662\right.$ to $\left.1653 \mathrm{~cm}^{-1}\right)$, and for the trans form at 5.96 to $6.05 \mu \mathrm{m}$ (1678 to 1653 $\mathrm{cm}^{-1}$. For example, trans-3-hexene-D-threo-1,2,5,6tetrol shows [28] a band at $6.05 \mu \mathrm{m}\left(1653 \mathrm{~cm}^{-1}\right)$. A terminal, exocyclic double bond, as in $\mathrm{H}_{2} \mathrm{C}=\mathrm{CRR}^{\prime}$, shows a band at 6.03 to $6.07 \mu \mathrm{m}$ (1658 to $1648 \mathrm{~cm}^{-1}$ ), and for $\mathrm{H}_{2} \mathrm{C}=\mathrm{CHR}$ at 6.07 to $6.11 \mu \mathrm{m}$ (1648 to $1638 \mathrm{~cm}^{-1}$ ).

The unsubstituted phenyl ring $\left(\mathrm{C}_{6} \mathrm{H}_{5}\right)$ shows bands of medium, variable intensity for skeletal, in-plane, stretching vibrations of aryl $\mathrm{C}=\mathrm{C}$ at 6.16 to $6.35 \mu \mathrm{m}$ (1625 to $1575 \mathrm{~cm}^{-1}$ ), 6.29 to 6.36 $\mu \mathrm{m}$ (1590 to $1575 \mathrm{~cm}^{-1}$ ), 6.38 to $6.94 \mu \mathrm{m}$ (1465 to $1440 \mathrm{~cm}^{-1}$ ), and 6.56 to $6.78 \mu \mathrm{m}$ (1525 to 1475 $\mathrm{cm}^{-1}$ ). Thus, the phenyl (monosubstituted benzene) ring of the benzoyl group shows bands at 6.25 and $6.32 \mu \mathrm{m}$ (1600 and $\left.1584 \mathrm{~cm}^{-1}\right)$. For example, a group of 1-acylamido sugar derivatives having $N$-benzoyl or $O$-benzoyl groups, or both, showed [2] bands at 6.20 to $6.25 \mu \mathrm{m}$ (1613 to 1600 $\mathrm{cm}^{-1}$ ), 6.30 to $6.38^{\circ} \mu \mathrm{m}$ (1587 to $1567 \mathrm{~cm}^{-1}$ ), and 
6.64 to $6.77 \mu \mathrm{m}$ (1506 to $1477 \mathrm{~cm}^{-1}$ ); and the $p$-substituted phenyl ring of $p$-toluenesulfonic esters of alditols [26] and sugars [27] shows an aryl $\mathrm{C}=\mathrm{C}$ band at 6.23 to $6.25 \mu \mathrm{m}$ (1605 to 1600 $\mathrm{cm}^{-1}$ ) which differentiates them from methanesulfonates.

\subsection{5 $\mathrm{C} \equiv \mathrm{N}, \mathrm{C}=\mathrm{N}$, and $\mathrm{C}-\mathrm{N}$ Bands}

The stretching band for $\mathrm{C} \equiv \mathrm{N}$ lies in the range of 4.17 to $4.76 \mu \mathrm{m}$ (2400 to $2100 \mathrm{~cm}^{-1}$ ); thus, for $\mathrm{R}-\mathrm{C} \equiv \mathrm{N}$, it is found at 4.43 to $4.47 \mu \mathrm{m}$ (2260 to $2240 \mathrm{~cm}^{-1}$ ), and, for conjugated $\mathrm{R}-\mathrm{C} \equiv \mathrm{N}$, at 4.47 to $4.52 \mu \mathrm{m}\left(2240\right.$ to $\left.2215 \mathrm{~cm}^{-1}\right)$. For isocyanides, $\mathrm{R}-\mathrm{N} \equiv \mathrm{C}$, the band is at 4.55 to 4.76 $\mu \mathrm{m}\left(2200\right.$ to $\left.2100 \mathrm{~cm}^{-1}\right)$. For $-\mathrm{S}-\mathrm{C} \equiv \mathrm{N}$, the band is found at ca. $4.63 \mu \mathrm{m}\left(c a .2160 \mathrm{~cm}^{-1}\right)$.

Compounds containing $\mathrm{C}=\mathrm{N}$ - show a band at 6.02 to $6.21 \mu \mathrm{m}\left(1660\right.$ to $\left.1610 \mathrm{~cm}^{-1}\right)$ that has been used in determining whether such compounds as $N$-substituted glycosylamines are cyclic or acyclic (see p. 18). However, the compound examined must be scrupulously dry, as moisture shows a band at 6.06 to $6.25 \mu \mathrm{m}$ (1650 to $\left.1600 \mathrm{~cm}^{-1}\right)$. Moreover, hydrates cannot be employed, as water of crystallization shows a band at 6.06 to $6.10 \mu \mathrm{m}$ (1650 to $1640 \mathrm{~cm}^{-1}$ ).

For $-\mathrm{N}=\mathrm{C}=\mathrm{S}$ (isothiocyanate) and $-\mathrm{N}=\mathrm{C}=\mathrm{N}^{\top}-$ (carbodiimides), a strong band is shown at ca. $4.76 \mu \mathrm{m}\left(c a .2100 \mathrm{~cm}^{-1}\right)$.

Aliphatic amines show a medium-intensity band for $\mathrm{C}-\mathrm{N}$ stretching at 8.20 to $9.80 \mu \mathrm{m}$ (1220 to $1020 \mathrm{~cm}^{-1}$ ) and a reak band at about $7.90 \mu \mathrm{m}$ $\left(1410 \mathrm{~cm}^{-1}\right)$. Nitro compounds show a band (medium intensity) for $\mathrm{C}-\mathrm{N}$ stretching at 10.87 to $11.76 \mu \mathrm{m}$ (920 to $850 \mathrm{~cm}^{-1}$ ), and primary amides at 7.05 to $7.15 \mu \mathrm{m}$ (1418 to $1400 \mathrm{~cm}^{-1}$ ). Of less diagnostic value are a $\mathrm{C}-\mathrm{N}$ band at 7.30 to $7.63 \mu \mathrm{m}$ (1370 to $1310 \mathrm{~cm}^{-1}$ ) for the $N$-methyl group, and the $\mathrm{Ph}-\mathrm{N}$ stretching band, observed [33] at 8.70 to $8.84 \mu \mathrm{m}$ (1149 to $1131 \mathrm{~cm}^{-1}$ ) or [34] 8.62 to $8.85 \mu \mathrm{m}$ (1160 to $1130 \mathrm{~cm}^{-1}$ ), for phenylhydrazones and phenylazo derivatives.

\subsection{6. $\mathrm{C}=\mathrm{O}$ Bands}

(a) Aldehydes and Ketones.-The $\mathrm{C}=\mathrm{O}$ stretching frequency for the carbonyl group of aldehydes and ketones lies at 5.78 to $6.00 \mu \mathrm{m}\left(1730\right.$ to $\left.1665 \mathrm{~cm}^{-1}\right)$. Thus, for the acyclic form of certain aldoses and ketoses (in a lyophilizate of the mutarotational equilibrium mixture), an extremely weak band is detectable [13] at $5.82 \mu \mathrm{m}\left(1718 \mathrm{~cm}^{-1}\right)$. Kuhn [14] attributed a band at $6.2 \mu \mathrm{m}\left(1613 \mathrm{~cm}^{-1}\right)$ shown by periodate-oxidized methyl $\alpha$-D-glucopyranoside to aldehydic carbonyl. Periodate-oxidized cellulose shows only a very weak band [35], and has been shown [36] to exist mainly as the hemialdal $-\mathrm{CH}-(\mathrm{OH})-\mathrm{O}-\mathrm{CH}(\mathrm{OH})$ - , formed by hydration of two aldehyde groups per oxidized residue.

If the bands given by two different kinds of groups lie in close proximity in the spectrum (see table 1), the bands may be separate, but often one appears as a shoulder on the other, or one may completely obscure the other. For example, a number of anhydrous, monomeric, aldehydo sugar acetates show no strong band [17] for the aldehyde carbonyl group, presumably because it is obscured by the acetate carbonyl band. As a corollary, in the absence of other information, the CHO band could be mistaken for $\mathrm{OAc}$ or $\mathrm{OBz}$. If such interference is absent, aldehydo and keto sugars show the $\mathrm{C}=\mathrm{O}$ band; for example, 3-O-benzyl-1,2-Oisopropylidene- $\alpha$-D- $x y$ lo-pentodialdo- 1,4 -furanose shows [37] a band at $5.8 \mu \mathrm{m}\left(1724 \mathrm{~cm}^{-1}\right)$.

(b) Un-ionized Carboxylic Acids.-The $\mathrm{C}=\mathrm{O}$ stretching frequency appears at $5.76 \mu \mathrm{m}$ (1736 $\left.\mathrm{cm}^{-1}\right)$ for $-\mathrm{C}(=\mathrm{O}) \mathrm{OH}$ of un-ionized carboxylic acids $[38,39]$, including alginic acid, chrondroitin sulfate, hyaluronic acid, and the pneumococcal polysaccharides.

(c) Lactones.-In 1958, Barker et al. [40] found that 22 out of 24 aldono-1,4-lactones showed a band at 5.59 to $5.67 \mu \mathrm{m}$ (1790 to $1765 \mathrm{~cm}^{-1}$ ), and all of 11 aldono-1,5-lactones showed a band at 5.68 to $5.79 \mu \mathrm{m}\left(1760\right.$ to $\left.1726 \mathrm{~cm}^{-1}\right)$. Consequently, if the spectrum shows a strong band at $5.60 \mu \mathrm{m}$ $\left(1785 \mathrm{~cm}^{-1}\right)$, there is a strong possibility that the aldonolactone is 1,4 and if it shows a band at 5.78 $\mu \mathrm{m}\left(1730 \mathrm{~cm}^{-1}\right)$, there is a possibility that it is 1,5 . However, if it shows a band at 5.65 to $5.70 \mu \mathrm{m}$ (1770 to $1775 \mathrm{~cm}^{-1}$ ), some other method for distinguishing between the two should be used. The 6,3 -lactones of 1,2-O-isopropylidene- $\alpha$-D-gluco- and $-\beta$-L-ido-furanuronic acid show [4] $\mathrm{C}=\mathrm{O}$ stretching [41] at 5.59 to $5.67 \mu \mathrm{m}$ (1790 to $\left.1765 \mathrm{~cm}^{-1}\right)$.

(d) Acetates and Other Esters.-The $\mathrm{C}=\mathrm{O}$ stretching vibration of the $O$-acetyl group gives rise to strong absorption at 5.72 to $5.80 \mu \mathrm{m}$ (1748 to $\left.1724 \mathrm{~cm}^{-1}\right)$; thus, the octaacetates of $\alpha$-cellobiose, $\alpha$-gentiobiose, and $\beta$-maltose show [42] a strong band at $5.79 \mu \mathrm{m}\left(1727 \mathrm{~cm}^{-1}\right), 5.72 \mu \mathrm{m}$ $\left(1748 \mathrm{~cm}^{-1}\right)$, and $5.76 \mu \mathrm{m}\left(1736 \mathrm{~cm}^{-1}\right)$, respectively. Similarly, six acetates of cyclic acetals of sugars showed [4] a band at 5.72 to $5.75 \mu \mathrm{m}$ (1748 to 1739 $\left.\mathrm{cm}^{-1}\right)$; all of 24 acetylated aldopyranosides showed [18] at least one band in the region of 5.67 to 5.76 $\mu \mathrm{m}$ (1764 to $1736 \mathrm{~cm}^{-1}$ ); all of 8 reducing, pyranose acetates showed [19] a band at 5.71 to $5.76 \mu \mathrm{m}$ (1751 to $1736 \mathrm{~cm}^{-1}$ ); all of 20 fully acetylated pyranoses [20] showed a band at 5.69 to $5.74 \mu \mathrm{m}$ (1757 to $1742 \mathrm{~cm}^{-1}$ ); and, for 14 acetates (and a tetrapropionate) of 1-acylamido derivatives of sugars, all showed [2] a band at 5.68 to $5.74 \mu \mathrm{m}$ (1761 to $1742 \mathrm{~cm}^{-1}$ ), except for $N$-acetyl-2,3,4-tri$O$-acetyl- $\beta$-D-ribosylamine, showing [43] a band at $5.82 \mu \mathrm{m}\left(1718 \mathrm{~cm}^{-1}\right)$. Benzoates of the same group of 1-acylamido derivatives showed [2] a band at 5.73 to $5.79 \mu \mathrm{m}\left(1745\right.$ to $\left.1727 \mathrm{~cm}^{-1}\right)$, except for 1,1-bis(benzamido)-6-O-benzoyl-1-deoxyD-glucitol, showing a band at $5.89 \mu \mathrm{m}\left(1698 \mathrm{~cm}^{-1}\right)$. Mixed esters (acetate-benzoates) showed two bands in this region.

The five-membered, cyclic carbonate group in sugar carbonates shows an enhanced $\mathrm{C}=\mathrm{O}$ stretching frequency as compared with the mixedester carbonates of sugars, average values lying at $5.49 \mu \mathrm{m}\left(1820 \mathrm{~cm}^{-1}\right)$ and $5.68 \mu \mathrm{m}\left(1760 \mathrm{~cm}^{-1}\right)$, 
respectively [44]. If the cyclic carbonate is transfused in sugar derivatives, a strong $\mathrm{C}=\mathrm{O}$ stretching band is shown [45] at $5.43 \mu \mathrm{m}\left(1842 \mathrm{~cm}^{-1}\right)$; the band is not shown by cis-fused carbonates.

(e) Primary Amides.- The $\mathrm{C}=\mathrm{O}$ stretching frequency for $-\mathrm{C}(=\mathrm{O}) \mathrm{NH}_{2}$ lies near $6.06 \mu \mathrm{m}$ $\left(1650 \mathrm{~cm}^{-1}\right)$ for solids, and near $5.92 \mu \mathrm{m}$ (1690 $\mathrm{cm}^{-1}$ ) for dilute solutions. It is known as the Amide I band, and is also shown by secondary and tertiary amides. Three glycopyranuronamide derivatives showed [19] this band at 6.00 to 6.02 $\mu \mathrm{m}\left(1667\right.$ to $\left.1661 \mathrm{~cm}^{-1}\right)$.

(f) N-Acetyl and S-Acetyl.-The Amide I band for the monosubstituted amide group, as in $-\mathrm{NH}-(\mathrm{C}=\mathrm{O})-\mathrm{CH}_{3}$, occurs at $c a .6 .04 \mu \mathrm{m}(1655$ $\mathrm{cm}^{-1}$ ) for solids, and at 5.88 to $5.99 \mu \mathrm{m}$ (1700 to $1670 \mathrm{~cm}^{-1}$ ) for dilute solutions. Thus, the anomers of 2-acetamido-2-deoxy-D-glucopyranose and their tetraacetates show [46] the band at 5.97 to 6.19 $\mu \mathrm{m}\left(1675\right.$ to $\left.1616 \mathrm{~cm}^{-1}\right)$. For all of 161 -acetamido derivatives of sugars, the band is shown [19] at 5.85 to $6.02 \mu \mathrm{m}$ (1709 to $\left.1661 \mathrm{~cm}^{-1}\right)$. Hydrates showed bands at 6.01 to $6.09 \mu \mathrm{m}$ (1664 to 1642 $\mathrm{cm}^{-1}$ ) that overlapped, somewhat obscured, or were obscured by, Amide I bands in the same region. Of 60 1-acylamido derivatives of sugars, all showed [2] a band at 5.95 to $6.15 \mu \mathrm{m}$ (1681 to $\left.1626 \mathrm{~cm}^{-1}\right)$. 'The Amide I band occurs near' 6.07 $\mu \mathrm{m}\left(1648 \mathrm{~cm}^{-1}\right)$ for such polysaccharides as chitin [47], but at $6.18 \mu \mathrm{m}\left(1618 \mathrm{~cm}^{-1}\right)$ for 2acetamido-2-deoxy- $\alpha$-D-glucopyranose, and at 6.01 $\mu \mathrm{m}\left(1665 \mathrm{~cm}^{-1}\right)$ for its tetraacetate, probably because of differences in the hydrogen bonding between the $\mathrm{C}=\mathrm{O}$ group and $\mathrm{OH}$ and $\mathrm{NH}$ groups [3]. Because an ionized carboxyl group will absorb in this region, the spectra of such polysaccharides as chrondroitin sulfate should be recorded for films cast from an acid solution.

The carbonyl group in the $S$-acetyl group, $-\mathrm{S}-(\mathrm{C}=\mathrm{O})-\mathrm{CH}_{3}$, shows [48] a band near 5.95 $\mu \mathrm{m}\left(1680 \mathrm{~cm}^{-1}\right)$. Thus, this group can be distinguished from the $O$-acetyl group, absorbing near $5.75 \mu \mathrm{m}\left(1740 \mathrm{~cm}^{-1}\right)$ and the $N$-acetyl group, absorbing near $6.10 \mu \mathrm{m}\left(1640 \mathrm{~cm}^{-1}\right)$.

\subsection{7. $\mathrm{C}-\mathrm{O}$ Bands}

(a) Esters.-Strong bands for the C-O stretching vibrations are shown by esters; for example, by acetates at 8.00 to $8.13 \mu \mathrm{m}\left(1250\right.$ to $\left.1230 \mathrm{~cm}^{-1}\right)$, formates at 8.33 to $8.48 \mu \mathrm{m}\left(1200\right.$ to $\left.1180 \mathrm{~cm}^{-1}\right)$, and propionates at 8.33 to $8.55 \mu \mathrm{m}(1200$ to 1170 $\mathrm{cm}^{-1}$. Esters of aromatic acids shows two strong bands for $\mathrm{C}-\mathrm{O}$ stretching, at 7.69 to $8.00 \mu \mathrm{m}$ (1300 to $1250 \mathrm{~cm}^{-1}$ ) and 8.70 to $9.09 \mu \mathrm{m}(1150$ to $\left.1100 \mathrm{~cm}^{-1}\right)$.

(b) Carboxylate Ion. - Salts of carboxylic acids, such as the lithium and barium salts of 1,2-Oisopropylidene- $\alpha$-D-glucofuranuronic acid, show [4] a carbon-oxygen stretching band (strong) at 6.11 to $6.25 \mu \mathrm{m}$ (1637 to $1600 \mathrm{~cm}^{-1}$ ) that distinguishes carboxylate anions from the $\mathrm{C}=\mathrm{O}$ stretching band of esters, and a band (medium strength) at 7.04 to $7.69 \mu \mathrm{m}\left(1420\right.$ to $\left.1300 \mathrm{~cm}^{-1}\right)$.

\subsection{8. $\mathrm{N} \equiv \mathrm{N}, \mathrm{N}=\mathrm{N}$, and $\mathrm{NO}_{2}$ Bands}

The $\mathrm{N} \equiv \mathrm{N}$ stretching vibration of azides gives a strong band at 4.63 to $4.72 \mu \mathrm{m}$ (2160 to 2120 $\left.\mathrm{cm}^{-1}\right)$ and a weak band at 7.46 to $8.48 \mu \mathrm{m}(1340$ to $1180 \mathrm{~cm}^{-1}$ ). The $\mathrm{N}=\mathrm{N}$ group in aromatic diazo compounds gives bands at 6.31 to $6.37 \mu \mathrm{m}$ (1585 to $1570 \mathrm{~cm}^{-1}$ ) and at 7.04 to $7.24 \mu \mathrm{m}$ (1420 to $1381 \mathrm{~cm}^{-1}$ ). According to Bassignana and Cogrossi [34], the bands lie at 6.32 to $6.42 \mu \mathrm{m}$ (1582 to $1558 \mathrm{~cm}^{-1}$ ) and 6.95 to $7.25 \mu \mathrm{m}$ (1439 to $\left.1379 \mathrm{~cm}^{-1}\right)$.

Nitric esters of sugars show [27] strong bands for asymmetric $\mathrm{NO}_{2}$ stretching at 6.00 to $6.20 \mu \mathrm{m}$ (1667 to $1613 \mathrm{~cm}^{-1}$ ) and for symmetric $\mathrm{NO}_{2}$ stretching at 7.78 to $7.89 \mu \mathrm{m}\left(1285\right.$ to $\left.1267 \mathrm{~cm}^{-1}\right)$; a broad band (for $\mathrm{O}-\mathrm{NO}_{2}$ stretching) at 11.48 to $12.08 \mu \mathrm{m}$ (871 to $828 \mathrm{~cm}^{-1}$ ) is useful only for confirmation as it occurs in a region that contains bands ('Types 2a, 2c, and C) for sugars and the $\mathrm{C}-\mathrm{H}$ out-of-plane deformation of the $p$-substituted phenyl group.

\subsection{9. $\mathrm{S}=\mathrm{O},-\mathrm{SO}_{2}-$, and $\mathrm{C}=\mathrm{S}$ Bands}

Esters of sulfuric acid, such as the 6-sulfates of D-glucose, D-galactose, and 2-acetamido-2-deoxyD-glucose, show [49] an intense band at $8.07 \mu \mathrm{m}$ $\left(1240 \mathrm{~cm}^{-1}\right)$, due to $\mathrm{S}-\mathrm{O}$ stretching vibrations. The position of a band at 11.76 to $12.19 \mu \mathrm{m}(850$ to $820 \mathrm{~cm}^{-1}$ ) for the $\mathrm{C}-\mathrm{O} \rightarrow \mathrm{S}$ frequency of the sulfate group has been correlated with its attachment (primary or secondary) and with the axial or equatorial disposition if secondary (see page 16).

Sulfones show strong bands at 7.38 to 7.64 $\mu \mathrm{m}$ (1355 to $1310 \mathrm{~cm}^{-1}$ ) and 8.62 to $9.01 \mu \mathrm{m}$ (1160 to $1110 \mathrm{~cm}^{-1}$ ) for $\mathrm{S}=\mathrm{O}$ stretching; thus, the monosulfone obtained by oxidizing penta- $O$ acetyl-aldehydo-D-glucose dibenzyl dithioacetal shows a band at $7.66 \mu \mathrm{m}\left(1305 \mathrm{~cm}^{-1}\right)$ [22]

$p$-Toluenesulfonic esters of alditols [26] show bands at 7.3 to $7.4 \mu \mathrm{m}\left(1370\right.$ to $\left.1350 \mathrm{~cm}^{-1}\right)$ and at 8.4 to $8.5 \mu \mathrm{m}\left(1190\right.$ to $\left.1175 \mathrm{~cm}^{-1}\right)$ for the asymmetrical and symmetrical stretching modes of the $-\mathrm{SO}_{2}-$ group $[50,51]$. Sulfonic esters of sugars usually show two bands in each region [27]. Bands for $\mathrm{C}-\mathrm{O}-\mathrm{S}$ at 11.8 to $11.9 \mu \mathrm{m}$ (848 to $840 \mathrm{~cm}^{-1}$ ) and 11.2 to $11.4 \mu \mathrm{m}$ (893 to $877 \mathrm{~cm}^{-1}$ ) have been correlated with the axial or equatorial disposition of the sulfonic ester group (see page 16).

The $\mathrm{C}=\mathrm{S}$ group of thionocarbonates shows [52] bands at $7.52 \mu \mathrm{m}\left(1330 \mathrm{~cm}^{-1}\right)$ and at $7.65 \mu \mathrm{m}$ $\left(1307 \mathrm{~cm}^{-1}\right)$; a band at $8.40 \mu \mathrm{m}\left(1190 \mathrm{~cm}^{-1}\right)$ is also found [51].

Dimethylthiocarbamates of sugars show, for $\mathrm{OC}(=\mathrm{S}) \mathrm{NMe}_{2}$, a strong band [53] at 6.5 to 6.6 $\mu \mathrm{m}$ (1540 to $\left.1515 \mathrm{~cm}^{-1}\right)$. N,N-Dimethyldithiocarbamates show, for $-\mathrm{SC}(=\mathrm{S}) \mathrm{NMe}_{2}$, a strong band at 6.71 to $6.80 \mu \mathrm{m}\left(1490\right.$ to $\left.1470 \mathrm{~cm}^{-1}\right)$. 


\subsubsection{Miscellaneous Bands}

The following bands are useful. (1) Polystyrene (for calibration) : $3.51 \mu \mathrm{m}\left(2851 \mathrm{~cm}^{-1}\right), 6.24 \mu \mathrm{m}$ $\left(1602 \mathrm{~cm}^{-1}\right)$, and $11.03 \mu \mathrm{m}\left(907 \mathrm{~cm}^{-1}\right)$. (2) Nujol: $3.43 \mu \mathrm{m}\left(2918 \mathrm{~cm}^{-1}\right), 3.50 \mu \mathrm{m}\left(2861 \mathrm{~cm}^{-1}\right), 6.86$ $\mu \mathrm{m}\left(1458 \mathrm{~cm}^{-1}\right)$, and $7.26 \mu \mathrm{m}\left(1378 \mathrm{~cm}^{-1}\right)$ [and a weak band at $\left.13.89 \mu \mathrm{m}\left(720 \mathrm{~cm}^{-1}\right)\right]$. (3) Water as moisture: $2.92 \mu \mathrm{m}\left(3430 \mathrm{~cm}^{-1}\right)$ and $6.06-6.25 \mu \mathrm{m}$ (1650 to $1600 \mathrm{~cm}^{-1}$ ).

Spurious bands may be introduced by a variety of causes, including silicone grease used on stopcocks, polyethylene powder from laboratory ware, and phthalic anhydride from the plasticizer in plastic tubing. About 35 spurious bands have been listed [54].

\subsection{Correlations for the Fingerprint Region and Beyond}

\subsubsection{The Fingerprint Region}

Whereas the spectra of structurally similar compounds may be quite similar in the range of 2 to $7 \mu \mathrm{m}\left(5000\right.$ to $\left.1430 \mathrm{~cm}^{-1}\right)$, significant spectral differences are found in the fingerprint region from 7 to $11 \mu \mathrm{m}$ (1430 to $910 \mathrm{~cm}^{-1}$ ), because here the bands are due both to certain stretching vibrations and bending vibrations. As a result, small differences in structure appear as large spectral effects. Consequently, the region is valuable for identification of a compound, and for differentiating between isomers, including anomers.

On the other hand, the fingerprint region is often less useful for recognizing the presence of particular organic groups than the region below $7 \mu \mathrm{m}$ (above $1430 \mathrm{~cm}^{-1}$ ), where the presence or absence of bands may give valuable, reliable evidence for characteristic groups. For example, the characteristic group-frequencies for $\alpha$-(D or L)glucopyranose are essentially the same as those for $\beta$-(D or $\mathrm{L}$ )-glucopyranose, and hence their spectra below $7 \mu \mathrm{m}$ (above $1430 \mathrm{~cm}^{-1}$ ) are similar; but, for crystals in which the molecules have the favored chair conformation, the interactions of the hydroxyl group at C-1 with the ring-oxygen atom of a neighboring molecule can be expected to be different for the axially attached group of the $\alpha-(\mathrm{D}$ or $\mathrm{L})$ anomer and the equatorially attached group of the $\beta$-( $(\mathrm{D}$ or $\mathrm{L})$ anomer, and therefore their spectra in the fingerprint region can be expected to differ. In the hydrogenbonded structure proposed [55] for crystalline $\alpha$-D-glucopyranose, the bonding between the C-1 hydroxyl group of one molecule and the ring oxygen atom of a neighbor would be different from that for the crystalline $\beta$-D anomer. Analysis of such differences by a combination of x-ray crystal-structure analysis, broad-line nuclear magnetic resonance spectroscopy, and infrared spectroscopy should eventually lead to improved interpretation of the bands in the fingerprint region and beyond, but this goal has not yet been reached.

\subsubsection{Correlations for 10 to $15 \mu \mathrm{m}\left(1000\right.$ to $\left.667 \mathrm{~cm}^{-1}\right)$}

(a) Correlations for Certain Aldopyranose Derivatives.-In a part of the fingerprint range, namely, 10.42 to $13.70 \mu \mathrm{m}\left(960\right.$ to $\left.730 \mathrm{~cm}^{-1}\right)$, Barker and co-workers [56-58] have sought infrared bands characteristic of several aldopyranoses and their derivatives. In the first of these articles, they identified [56], for D-glucopyranose derivatives, three principal sets of bands, given in table 2 . These were: for $\alpha$ anomers, type 1a, $917 \pm 13$ $\mathrm{cm}^{-1}$; type $2 \mathrm{a}, 844 \pm 8 \mathrm{~cm}^{-1}$; and type $3 \mathrm{a}, 766 \pm 10$ $\mathrm{cm}^{-1}$; and for $\beta$ anomers, type $1 \mathrm{~b}, 920 \pm 5 \mathrm{~cm}^{-1}$; type $2 \mathrm{~b}, 891 \pm 7 \mathrm{~cm}^{-1}$; and type $3 \mathrm{~b}, 774 \pm 9 \mathrm{~cm}^{-1}$.

If the bands are to have diagnostic value for (D or L)-glucopyranose derivatives, $\alpha$ anomers should not show type $2 \mathrm{~b}$ absorption, and $\beta$ anomers should not show type 2 a absorption. However, they found [56] that (a) some $\alpha$ anomers exhibit type 1 absorption in the range of type $2 \mathrm{~b}$ bands, and (b) some $\beta$ anomers show "weak peaks of type $2 a$ " which they believed were due to traces of the $\alpha$ anomers. They found that the type $2 \mathrm{a}$ band can be used with considerable con-

TABle 2. Positions (mean values) of various types of bands for D-glucopyranose derivatives [56]

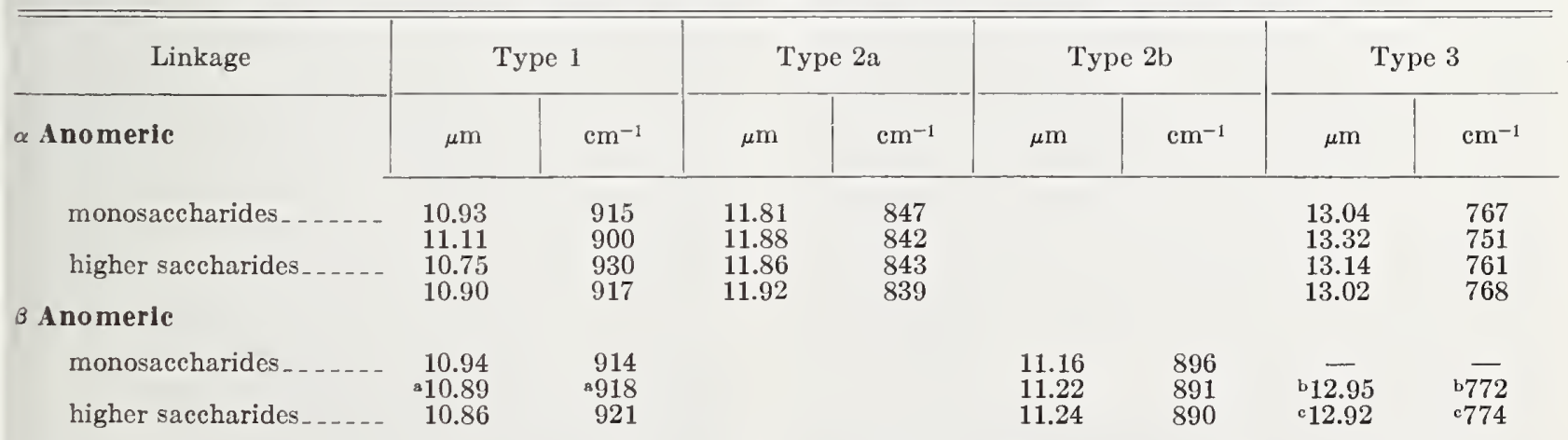

a Six of ten compounds did not show this band. ${ }^{b}$ Eleven of sixteen compounds did not show this band. ${ }^{c}$ Five of sixteen compounds did not show this band. 
TABLE 3. Infrared bands (mean values) shown by five (D or L)-aldopyranoses and their derivatives [56, 57]

\begin{tabular}{|c|c|c|c|c|c|c|c|c|c|c|}
\hline \multirow{2}{*}{ Type of band } & \multicolumn{2}{|c|}{ Xylose } & \multicolumn{2}{|c|}{ Arabinose } & \multicolumn{2}{|c|}{ Glucose } & \multicolumn{2}{|c|}{ Mannose } & \multicolumn{2}{|c|}{ Galactose } \\
\hline & $\mu \mathrm{m}$ & $\mathrm{cm}^{-1}$ & $\mu \mathrm{m}$ & $\mathrm{cm}^{-1}$ & $\mu \mathrm{m}$ & $\mathrm{cm}^{-1}$ & $\mu \mathrm{m}$ & $\mathrm{cm}^{-1}$ & $\mu \mathrm{m}$ & $\mathrm{cm}^{-1}$ \\
\hline
\end{tabular}

Both anomers

\begin{tabular}{|c|c|c|c|c|c|c|c|c|c|c|}
\hline 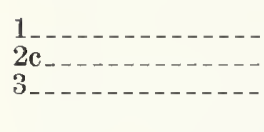 & $\stackrel{?}{-}$ & $\stackrel{?}{-}$ & $\frac{?}{13.11}$ & $\frac{?}{763}$ & $\begin{array}{c}10.90 \\
\overline{-} \\
\times 12.99 \\
\times 13.28\end{array}$ & $\begin{array}{r}917 \\
\frac{7}{870} \\
\therefore 753\end{array}$ & $\begin{array}{c}? \\
11.42 \\
\text { a } 12.64\end{array}$ & $\begin{array}{r}? \\
876 \\
\mathbf{7} 791\end{array}$ & $\begin{array}{l}? \\
11.48 \\
\times 13.30\end{array}$ & $\begin{array}{l}? \\
871 \\
\text { a } 752\end{array}$ \\
\hline Za & $\alpha \underline{\mathbf{a n}}$ & $\frac{5 \text { only }}{749}$ & - & - & $\begin{array}{l}\text { a } 11.85 \\
\text { a } 11.86\end{array}$ & $\begin{array}{l}\text { a } 844 \\
\text { a } 843\end{array}$ & a 12.00 & a 833 & a 12.12 & 15 \\
\hline
\end{tabular}

$\beta$ anomers only

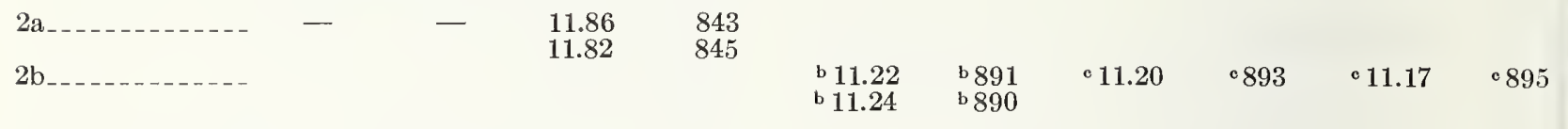

a Many derivatives containing a benzene ring absorb here. ${ }^{\mathrm{b}}$ Must be confirmed by absence of absorption at $c a .11 .85$ $\mu \mathrm{m}\left(\mathrm{ca} .844 \mathrm{~cm}^{-1}\right)$. ${ }^{\mathrm{e}}$ Bands for other types of vibration also occur here.

fidence for diagnosing the $\alpha$ anomeric form, particularly in polymers of glucopyranose. The type $2 \mathrm{~b}$ band was not found useful for diagnosing the $\beta$ anomeric form, but the absence of the type $2 a$ band was considered very useful for diagnosing the $\beta$ anomeric form. They regarded the bands of types 1 and 3 as only useful for determining points of linkage in polymers of $\alpha$-glucopyranose.

When the infrared spectra of additional glucopyranose derivatives were reported in their next paper [57], slightly different positions were found for bands of type $2 a$ and type 3 (see table 3 ). As before, some of the $\alpha$ anomers were found to show type 1 absorption in the range of type $2 b$ bands. Also, they pointed out that derivatives containing a phenyl ring may show absorption in the region of the type $2 \mathrm{a}$ band, and the acetates absorb in the region of the type $2 \mathrm{~b}$ band. Their results [57] for bands characteristic of four other aldopyranoses and their derivatives are also summarized in table 3 . With manno- and galactopyranose derivatives, the type 2 a band can be used for diagnosing $\alpha$ anomers; absence of the type $2 \mathrm{a}$ band is useful for diagnosing the $\beta$ anomeric form. A band at 11.30 to $11.53 \mu \mathrm{m}\left(876 \pm 9 \mathrm{~cm}^{-1}\right)$, designated type 2c, was found characteristic [57] of mannopyranose derivatives; and a band of type 2c, at 11.39 to $11.57 \mu \mathrm{m}\left(871 \pm 7 \mathrm{~cm}^{-1}\right)$, was considered characteristic of galactopyranose derivatives. The mean frequency for a given type of absorption may change with the group-configuration; thus, the mean for type 3 absorption is at $12.64 \mu \mathrm{m}\left(791 \mathrm{~cm}^{-1}\right)$ for the manno configuration, but at $13.30 \mu \mathrm{m}\left(752 \mathrm{~cm}^{-1}\right)$ for the gluco and galacto configurations.

In addition, Barker and co-ivorkers [58] found that 2- and 3-deoxy derivatives of gluco-, manno-, and galacto-pyranose show absorption at 11.51 to
$11.56 \mu \mathrm{m}$ (869 to $865 \mathrm{~cm}^{-1}$ ) ; seven 6-deoxy derivatives of mannopyranose or galactopyranose show a band near $10.34 \mu \mathrm{m}\left(967 \mathrm{~cm}^{-1}\right)$.

Application of these correlations [56-58] has proved useful [3] in the study of many related compounds, including oligo- and poly-saccharides. Assignments suggested [3,56-58] for the bands are given in table 4 . It should be noted, however, that, in the range of 10 to $15 \mu \mathrm{m}$ (1000 to 667 $\mathrm{cm}^{-1}$ ), methyl $\beta$-D-xylopyranoside shows only three bands [12], namely, at $10.25 \mu \mathrm{m}\left(976 \mathrm{~cm}^{-1}\right)$, $10.38 \mu \mathrm{m}\left(963 \mathrm{~cm}^{-1}\right)$, and $11.14 \mu \mathrm{m}\left(898 \mathrm{~cm}^{-1}\right)$; indeed, $\beta$-(D or L)-xylopyranose derivatives are not characterizable by any of the bands listed in table 3 . This example shows that the bands listed in tables 3 and 4 cannot be regarded as characteristic of the pyranoid ring, per se, of aldopyranoid derivatives.

(b) Correlations for Furanoid and Pyranoid Forms of Aldose and Ketose Derivatives.-For aldoand keto-furanose derivatives, Barker and Stephens [59] noted absorption bands at the following mean values: type $\mathrm{A}$, at $10.82 \mu \mathrm{m}$ (924 $\left.\mathrm{cm}^{-1}\right)$; and type D, at $12.52 \mu \mathrm{m}\left(799 \mathrm{~cm}^{-1}\right)$. Type A absorption could not be distinguished from types 1 or $2 b$ of aldopyranoses, and therefore has no diagnostic value in differentiating between furanoid and pyranoid aldoses. In addition, most of the furanoid compounds also showed type B absorption at $11.38 \mu \mathrm{m}\left(879 \mathrm{~cm}^{-1}\right)$ and type $\mathrm{C}$ absorption at $11.66 \mu \mathrm{m}\left(858 \mathrm{~cm}^{-1}\right)$. It has been found $[2,4,19]$ that these correlations are, in most instances, restricted to the compounds they: studied, and cannot be extended to have a wider diagnostic applicability to related compounds.

In 1962, the infrared spectra of most of the readily available, unsubstituted aldo- and ketopentoses and aldo- and keto-hexoses were pub- 
TABLE 4. Bands possibly characteristic of various features of some aldopyranose derivatives

\begin{tabular}{|c|c|c|c|c|}
\hline \multirow{2}{*}{$\begin{array}{l}\text { Type } \\
\text { of } \\
\text { band }\end{array}$} & \multirow{2}{*}{ Structural feature } & \multicolumn{2}{|c|}{ Bands a } & \multirow{2}{*}{$\begin{array}{l}\text { Refer- } \\
\text { ences }\end{array}$} \\
\hline & & $\mu \mathrm{m}$ & $\mathrm{cm}^{-1}$ & \\
\hline & $\begin{array}{l}\text { Terminal } C \text {-methyl- } \\
\text { group rocking } b\end{array}$ & 10.34 & 967 & {$[58]$} \\
\hline 1 - & $\begin{array}{l}\text { Antisymmetrical ring- } \\
\text { vibration c }\end{array}$ & 10. 90 & 917 & [56] \\
\hline $2 b_{-}$ & $\begin{array}{l}\text { Anomeric } \mathrm{C}-\mathrm{H} \text { axial } \\
\text { bond }\end{array}$ & 11. 22 & 891 & {$[56]$} \\
\hline $2 c_{-}$ & $\begin{array}{l}\text { Equatorial } \mathrm{C}-\mathrm{H} \\
\text { deformation (other } \\
\text { than anomeric } \mathrm{C}-\mathrm{H} \text { ) }\end{array}$ & 11. 36 & 880 & {$[57]$} \\
\hline & $\begin{array}{l}\text { Ring-methylene rocking } \\
\text { vibration (if not } \\
\text { adjacent to the ring- } \\
\text { oxygen atom) }\end{array}$ & 11. 53 & 867 & {$[58]$} \\
\hline $2 a_{-}$ & $\begin{array}{l}\text { Anomeric } \mathrm{C}-\mathrm{H} \\
\text { equatorial bond }\end{array}$ & 11.85 & 844 & {$[56]$} \\
\hline $3 \ldots$ & $\begin{array}{l}\text { Symmetrical ring- } \\
\text { breathing vibration }\end{array}$ & 12. 99 & 770 & {$[56]$} \\
\hline
\end{tabular}

a Mean value. $\mathrm{b}$ This band may not have diagnostic value. c For glucopyranose derivatives.

lished [13]. In 1964, Verstraeten [60] made a study of these spectra, together with those of some additional 2-ketoses, and obtained evidence that most of the common sugars having a cyclic structure, and their derivatives, display type 1 absorption at a mean value of $10.76 \mu \mathrm{m}$ (929 $\mathrm{cm}^{-1}$ ). Hence, the type 1 (type $\mathrm{A}$ ) band has no diagnostic value for distinguishing between aldoses and ketoses, and between glycofuranoses and glycopyranoses. Moreover, as the type 1 band is shown [2] by acyclic 1-acylamido derivatives of sugars, it has no diagnostic value for distinguishing between cyclic and acyclic forms of such compounds, either.

The same author [60] observed that some ketopyranoses, as well as aldopyranoses, show a type 3 band at $12.80 \mu \mathrm{m}\left(781 \mathrm{~cm}^{-1}\right)$. Hence, this band, too, has limited diagnostic value. He concluded that type 3 absorption is shown provided that two conditions are met: (a) the sugar inust have a pyranoid ring, and (b) this pyranoid form must assume a conformation having at least one axial hydroxyl group. If the number of axial hydroxyl groups is increased (thereby decreasing the conformational stability), type 3 absorption becomes manifest. For example, $\beta$ (D or L)-xylopyranose, which shows no type 3 absorption, is devoid of axial hydroxyl groups, whereas the $\alpha$ anomer in the favored conformation, which has an axial hydroxyl group at C-1 shows absorption at $13.16 \mu \mathrm{m}\left(760 \mathrm{~cm}^{-1}\right)$.

It was found [60] that 2-ketoses display "type I" bands at $11.44 \mu \mathrm{m}\left(874 \mathrm{~cm}^{-1}\right)$ and "type IIA" bands at $12.24 \mu \mathrm{m}\left(817 \mathrm{~cm}^{-1}\right)$, regardless of whether the 2-ketoses are pyranose or furanose.
These bands were ascribed to the presence of the following structural feature:

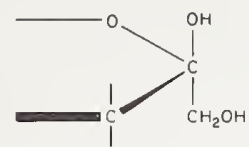

and were tentatively assigned to a skeletal vibration. However, six aldoses also show these bands. The type I band, which appears to be the same as Barker's type B band for aldo- and keto-furanoses at $11.38 \mu \mathrm{m}\left(879 \mathrm{~cm}^{-1}\right)$, has [2] no diagnostic value for 60 aldofuranoid, aldopyranoid, and acyclic 1-acylamido derivatives. The type IIA band lies in about the same range as Barker's type D band for aldo- and ketofuranose derivatives, which is at $12.52 \mu \mathrm{m}$ (799 $\mathrm{cm}^{-1}$ ). If the hydroxyl groups of a 2-ketofuranose are substituted, or if $\mathrm{C}_{-} 2$ of the 2-ketofuranose is joined to a pyranoid or furanoid structure, a type IIB band appears at $11.99 \mu \mathrm{m}\left(834 \mathrm{~cm}^{-1}\right)$, in addition to, or instead of, the type IIA band.

Verstraeten [60] found that only furanoses give "type 2" absorption at $11.76 \mu \mathrm{m}\left(850 \mathrm{~cm}^{-1}\right)$. He stated that his type 2 absorption is the same as the type $\mathrm{C}$ absorption of Barker and Stephens [59], and, to avoid confusion, it should be referred to as the latter. The type $\mathrm{C}$ band is given by both aldo- and keto-furanoses, and therefore cannot be used for distinguishirg betr een them.

It has been found [2] that, if an $N$-acetyl group (but no ester group) is present, the bands of types $\mathrm{C}, 3$, IIA, and IIB may have diagnos ic value; also, if an $N$-benzoyl group (but no es'er group) is present, the bands of types 3, IIA, and IIB may have diagnostic value. For $N$-acetyl- $O$-acetyl derivatives of sugars, the bands of typ ss IIA and IIB may differentiate between ketcses and nonketoses, but not between cyclic and acyclic compounds.

\subsection{Conformational Studies}

In studying the conformations of sugar derivatives, the most direct information is obtained by nuclear magnetic resonance spectroscopy. However, the empirical correlation of infrared spectra has been used [12] to give conformational information. Suppose that the spectra of the $\alpha$ and $\beta$ anomers of the methyl pyranosides of the 4 aldopentoses and 8 aldohexoses were to be recorded. This would provide 24 spectra of closely related compounds. Each cor $\mathrm{p}$ ) und has $\mathrm{C}-\mathrm{H}$, $\mathrm{C}-\mathrm{OH}, \mathrm{C}-\mathrm{OCH}_{3}$, and a pyranoid ring, and yet the spectrum of each is unique because the precise positions of the various bands change from one compound to another, depending on interactions arising from configuration and conformation and on the presence or absence of the hydroxymethyl group. 
As an example, the spectra of the $\alpha$ and $\beta$ anomers of methyl D-xylopyranoside and methyl L-arabinopyranoside were studied [12]. All bands shown in common by the four glycosides were ignored. All bands then shown in common by the two xylosides were regarded as characteristic of the xylo configuration and were ignored; similarly, all bands shown in common by the two arabinosides were ignored. This left a set of bands differentiating between the anomers of the xylosides, on the one hand, and between the arabinoside anomers, on the other (see table 5). This indicated a similarity between the $\beta$-D-xylopyranoside and the $\alpha$-L-arabinopyranoside. Since the conformation of methyl $\beta$-D-xylopyranoside has been shown [61] by $\mathrm{x}$-ray studies to be that depicted in fig. 4 , the conformational correlations are as indicated. These formulas are in agreement with the conformations predicted by considerations of interaction energies.
A

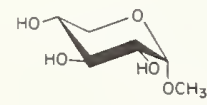

$c$

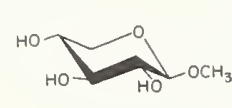

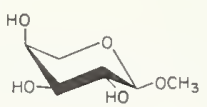

8

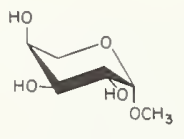

D
Figure 4. The structures of methyl $\beta$-D-xylopyranoside-CA (A) and methyl $\alpha$-L-arabinopyranoside- $C E(B)$ compared with those of methyl $\alpha-\mathrm{D}-x y l o p y r a n o s i d e-C A$ (C) and methyl $\beta$-L-arabinopyranoside-CE $(D)$.

This correlation is purely empirical, but the same kind of comparison has been made for other pairs of anomers of (a) methyl aldopyranosides [12], (b) acetylated methyl aldopyranosides [18], and (c) fully acetylated aldopyranoses [20]. In

TABLE 5. Anomer-differentiating bands $\left(\mathrm{cm}^{-1}\right)$ shown by four methyl pyranosides [12]

\begin{tabular}{|c|c|c|c|}
\hline \multicolumn{2}{|c|}{ D-xylo } & \multicolumn{2}{|c|}{ L-arabino } \\
\hline$\beta$ & $\alpha$ & $\alpha$ & $\beta$ \\
\hline $\begin{array}{r}3448 \\
1385 \\
1295 \\
1218 \\
1060 \\
976 \\
645 \\
473\end{array}$ & & $\begin{array}{r}3460 \\
1395 \\
1295 \\
1227 \\
1058 \\
973 \\
646 \\
487\end{array}$ & \\
\hline & $\begin{array}{r}3333 \\
2710 \\
741 \\
437\end{array}$ & & $\begin{array}{r}3322 \\
2695 \\
744 \\
433\end{array}$ \\
\hline
\end{tabular}

every instance, the empirical observations made on the infrared spectra agreed with the predicted conformations. With those sugar derivatives for which one chair conformation is not predicted to be strongly favored over the other, the resulting data did not fit in the correlations. Examples of the latter are: methyl $\alpha$ - and $\beta$-D-lyxopyranoside and their triacetates, methyl $\alpha$-D-gulopyranoside and its tetraacetate, and penta- $O$-acetyl- $\alpha-D-$ gulopyranose.

For a group of fully acetylated monosaccharides, those having an axial OAc at $\mathrm{C}-1$ showed [17] a band, possibly for a $\mathrm{C}-\mathrm{O}$ stretching vibration, at 8.59 to $8.67 \mu \mathrm{m}$ (1174 to $1153 \mathrm{~cm}^{-1}$ ); if the group was equatorial, a band was shown at $8.87 \mu \mathrm{m}$ $\left(1127 \mathrm{~cm}^{-1}\right)$. For each region, the other anomer showed the absorption only weakly or not at all. The results with compounds having the gulo, ido, and talo configurations indicated that they exist in the $\mathrm{CE}$ conformation, or as a mixture of the chair conformations.

For acetylated methyl glycosides [17], those having an axial $\mathrm{OMe}$ at $\mathrm{C}-1$ showed bands at 8.31 to $8.35 \mu \mathrm{m}\left(1203\right.$ to $1198 \mathrm{~cm}^{-1}$ ) and at 8.75 to $8.85 \mu \mathrm{m}$ (1143 to $1130 \mathrm{~cm}^{-1}$ ), but those having the group equatorial showed no absorption in either region.

Because polysulfated hyaluronic acid, which has equatorial sulfate groups only, shows a band at $12.19 \mu \mathrm{m}\left(820 \mathrm{~cm}^{-1}\right)$, Orr [39] concluded that the sulfate group of chondroitin sulfate $\mathrm{C}$, showing a band at $12.12 \mu \mathrm{m}\left(825 \mathrm{~cm}^{-1}\right)$, is equatorially attached, and that that of chondroitin sulfate A, giving a band at $11.70 \mu \mathrm{m}\left(855 \mathrm{~cm}^{-1}\right)$, is axially attached. He ascribed the bands to the $\mathrm{C}-\mathrm{O}-\mathrm{S}$ vibration. It was then found [62] that the equatorial sulfate group in D-glucose 3sulfate gives a band at $12.02 \mu \mathrm{m}\left(832 \mathrm{~cm}^{-1}\right)$, and that a band at $12.19 \mu \mathrm{m}\left(820 \mathrm{~cm}^{-1}\right)$ is shown by the 6-sulfates of D-galactose, D-glucose, and 2acetamido-2-deoxy-D-glucose, in which the ester group is on the equatorial, primary hydroxyl group. Hence, chondroitin sulfate $C$ (and D) probably has an equatorial sulfate group on C-6, and chondroitin sulfate $A$ (and B) has an axial sulfate group on C-4 of the 2-acetamido-2deoxy-D-galactose residues. Chondroitin polysulfate has sulfate groups at both C-4 and C-6.

Similarly, $\lambda$-carrageenan shows [63] a broad band at 11.62 to $12.35 \mu \mathrm{m}\left(860\right.$ to $\left.810 \mathrm{~cm}^{-1}\right)$, with a maximum at $12.09 \mu \mathrm{m}\left(827 \mathrm{~cm}^{-1}\right)$ compatible with the presence of residues of $D$-galactose 2,6-disulfate (diequatorial) and D-galactose 4sulfate (axial).

A strong band at 11.8 to $11.9 \mu \mathrm{m}$ (848 to 840 $\left.\mathrm{cm}^{-1}\right)$ and a weak one at 11.2 to $11.4 \mu \mathrm{m}(893$ to $877 \mathrm{~cm}^{-1}$ ) are shown by sulfonic esters of pyranoid sugars, and have been attributed [50] to the $\mathrm{C}-\mathrm{O}-\mathrm{S}$ vibration of an equatorial and an axial sulfonic ester group, respectively, on a pyranoid ring. 


\section{Examples of Use of Infrared Spectra}

In addition to those already mentioned, the following are some examples of the uses of infrared spectra.

\subsection{Qualitative}

Infrared spectra may be employed in following the course of a reaction. For example, if a compound requires several methylations to give a completely $\mathrm{O}$-methylated product, the extent of methylation may be determined by observing the disappearance of $\mathrm{OH}$ absorption from the infrared spectrum, so that quantitative determination for methoxyl need be made only on the final product.

The elementary approach has been applied [13] in studying the mutarotation of sugars. For a number of monosaccharides, an aqueous solution of one crystalline anomer was kept until mutarotation was complete; the solution was then lyophilized, and the spectrum of the lyophilizate was recorded and compared with those of the two crystalline anomers. For D-glucose, L-rhamnose, and D-mannose, all of the bands in the spectrum of the equilibrium mixture that are not shown by the $\alpha$-pyranose anomer are either (a) shown by the $\beta$-pyranose anomer or (b) could be due to overlapping and summation of closely situated bands of the two anomers, indicating that the equilibrium mixture consists of the anomers of the pyranose form; this conclusion is in agreement with the results of earlier, optical rotation studies by Isbell and Pigman [64]. In contrast, for D-talose, the spectrum of the lyophilizate showed bands absent from the spectrum of either anomer of the pyranose form. These results also agreed with those of the earlier work [65] (namely, that the equilibrium mixture contains the $\alpha$ - and $\beta$-furanose forms), and have since been confirmed, and quantified, by n.m.r. spectroscopy [66].

\subsection{Quantitative}

Mutarotation of sugars has also been studied quantitatively. Parker [67] recorded the spectra, for the range of 6.00 to $11.00 \mu \mathrm{m}$ (1667 to 909 $\left.\mathrm{cm}^{-1}\right)$, of 20 percent aqueous solutions of $\alpha$ D-glucose, $\beta$-D-glucose, and $\beta$-D-mannose: (a) 2.5 minutes after dissolution, and (b) at the end of mutarotation. By following the change in percent transmittance [at $8.75 \mu \mathrm{m}\left(1143 \mathrm{~cm}^{-1}\right)$ for $\alpha$ - and $\beta$-D-glucose, and at $8.60 \mu \mathrm{m}\left(1163 \mathrm{~cm}^{-1}\right)$ for $\beta$-Dmannose] with time, he was able to determine the mutarotation constants; these agreed well with those determined from measurements of change in optical rotation.

The intensity of a group frequency may be used for quantitative analysis, because it depends on the magnitude of the change in dipole moment that is associated with the molecular vibration. Consequently, strong bands are usually caused by the vibrations of polar linkages, such as $\mathrm{O}-\mathrm{H}$,

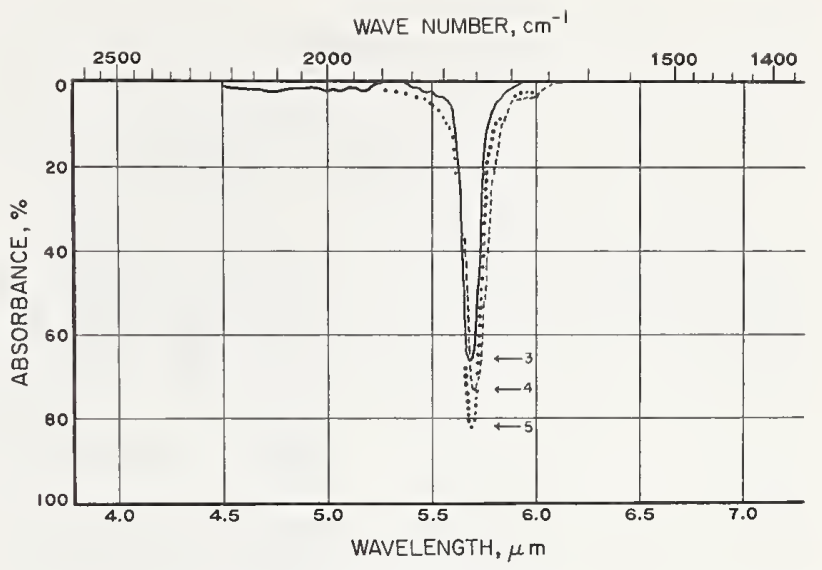

FIGURE 5. Infrared spectra of methyl tri-O-acetyl- $\alpha-\mathrm{L}-$ rhamnopyranoside (3), tetra-O-acetyl- $\beta-\mathrm{D}-$ mannopyranoside (4), and penta-O-acetyl-D-gly cero- $\beta$-D-gulo-heptopyranoside (5). All solutions 0.0197 M ( 9 and 5 in carbon tetrachloride; 4 in chloroform).

(From Ref. [17].)

$\mathrm{N}-\mathrm{H}, \mathrm{C}=\mathrm{O}, \mathrm{C}-\mathrm{N}$, etc. To a first approximation, the intensity of an absorption band characteristic of a specific group is proportional to the amount of that group present. Figure 5 shows part of the infrared spectra of equimolar solutions of three acetylated methyl glycopyranosides [17]. It may be seen that the area under the curve increasesfrom 3, to 4, to 5 acetyl groups. The procedure could be adapted for use as an analytical methodin this case, for acetyl; but any other group giving a characteristic band could similarly be analyzed for. In most cases, however, n.m.r. spectroscopy is a more convenient tool for such quantitative analysis, provided that a specific chemical-shift permits selected group integrations.

\subsection{Determination of Structure}

An example of solution of a structural problem involves the D-talose monobenzoate $(\mathbf{X})$ obtained [65] as a byproduct from the action of peroxybenzoic acid on D-galactal. There seemed a possibility that it might be a 1,2-(orthobenzoate) (3a), and so, its spectrum was compared [68] with that of 1,2-O-(1-methoxylethylidene)-Lrhamnose (4). As may be seen from figure 6, the latter has no band at $5.77 \mu \mathrm{m}\left(1733 \mathrm{~cm}^{-1}\right)$, whereas $\mathbf{X}$ has a strong ester-carbonyl absorption there. Hence, $\mathbf{X}$ is not an orthobenzoate but a benzoate; it was thought to be 1-O-benzoyl$\alpha$-D-talose, but was later [69] shown to be the $\beta$-D anomer (3).
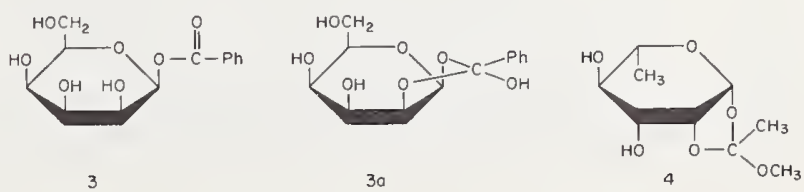


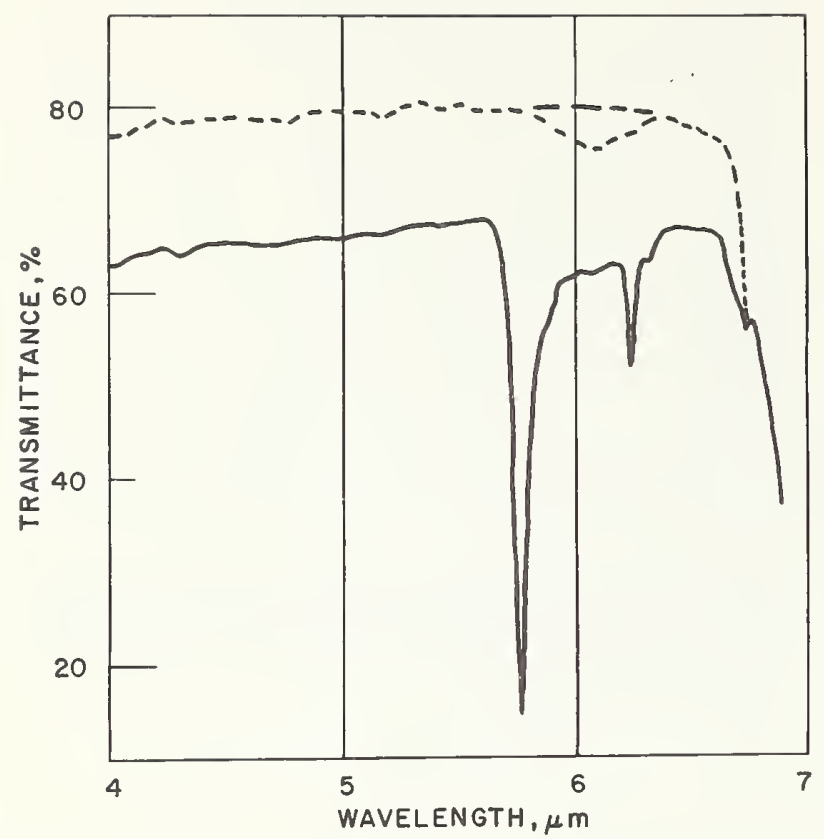

Figure 6. Infrared spectra of 1,2-0-(1-methoxyethylidene)$\mathrm{L}$-rhamnose $\left({ }_{-}--_{-}\right)$and 1 -O-benzoyl- $\beta$-D-talopyranose (-) in potassium chloride pellets.

(From Ref. [68].)

For sugars in which the hetero-atom of the ring may be nitrogen, the infrared spectra show immediately which form has this structure. For' example, for the two ring-forms of 5-acetamido5 -deoxy-L-arabinose [70], one form shows bands at $3.03 \mu \mathrm{m}\left(3300 \mathrm{~cm}^{-1}\right), 6.14 \mu \mathrm{m}\left(1630 \mathrm{~cm}^{-1}\right)$, and $6.43 \mu \mathrm{m}\left(1555 \mathrm{~cm}^{-1}\right)$, for $\mathrm{OH}$ and $\mathrm{NH}, \mathrm{NAc}$, and $\mathrm{NH}$, respectively, and is therefore the furanose form (5), whereas the other form shows bands at $2.96 \mu \mathrm{m}\left(3380 \mathrm{~cm}^{-1}\right)$ for $\mathrm{OH}$, and 6.19 and $6.27 \mu \mathrm{m}$ (1616 and $1595 \mathrm{~cm}^{-1}$ ) for NAc, but no - $\mathrm{NH}$ - absorption near $6.43 \mu \mathrm{m}$ (1555 $\mathrm{cm}^{-1}$, and is therefore the pyranose $(6)$.
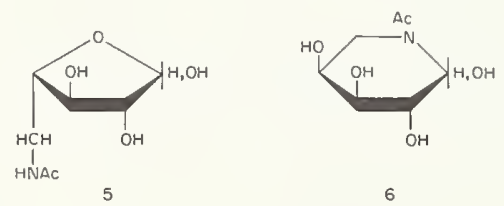

In another example, 4-acetamido-4,5-dideoxy2,3-O-isopropylidene-aldehydo-L-xylose shows bands [71] at $3.10 \mu \mathrm{m}\left(3226 \mathrm{~cm}^{-1} ; \mathrm{NH}\right), 5.81 \mu \mathrm{m}(1721$ $\left.\mathrm{cm}^{-1} ; \mathrm{CHO}\right), 6.10$ and $6.50 \mu \mathrm{m}$ (1639 and 1538 $\left.\mathrm{cm}^{-1} ; \mathrm{NHAc}\right)$, and $7.30 \mu \mathrm{m}\left(1370 \mathrm{~cm}^{-1} ; \mathrm{CMe}_{2}\right)$. On treatment of this compound $(y)$ with acetic acid, 4 -acetamido-4,5-dideoxy- $\alpha, \beta$-L-xylofuranose (8) was obtained; this compound (which cannot exist in a pyranoid form) shows $\mathrm{C}=\mathrm{O}$ absorption at $6.12 \mu \mathrm{m}\left(1634 \mathrm{~cm}^{-1}\right.$; Amide I).

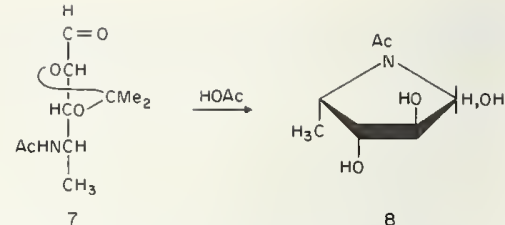

The Schiff-base structure (9) was proposed [72] for $N$-o-tolyl-D-glucosylamine, because it shows a $\mathrm{C}=\mathrm{N}$ band at $6.05 \mu \mathrm{m}\left(1653 \mathrm{~cm}^{-1}\right)$. However, the pure compound shows [15] no band at $6.05 \mu \mathrm{m}\left(1653 \mathrm{~cm}^{-1}\right)$, indicating that the structure is cyclic, probably the pyranoid form 10. All of the $N$-substituted glycosylamines examined by Ellis [15] were found, from their spectra, to have a cyclic structure.

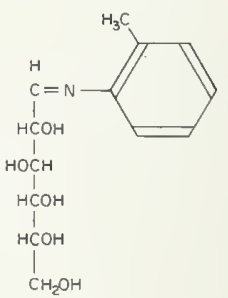

9

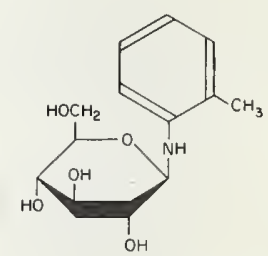

10
The oximes of arabinose [72], rhamnose [72], and fructose [73] show a weak band at $6.05 \mu \mathrm{m}(1653$ $\mathrm{cm}^{-1}$ ), which may indicate the acyclic form, but it is possible that the $\mathrm{N}-\mathrm{H}$ of the cyclic form might
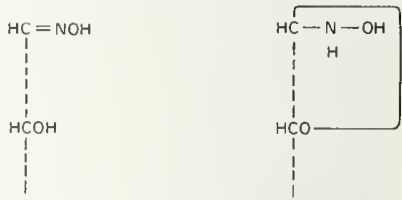

show a weak band of about the same frequency. D-Glucose oxime does not show a band in this region $[72,73]$, and is, presumably, cyclic. The acetyl derivatives of sugar oximes are undoubtedly cyclic, as they show the characteristic bands for the $N$ acetyl group [73].

Infrared spectroscopy has proved to be inappropriate for determining whether $N^{2}$-substituted hydrazones of sugars are cyclic ol acyclic. Even for $N^{2}$-substituted hydrazones that are known to be acyclic, the intensity of the $\mathrm{C}=\mathrm{N}$ band is so weak as to be unobservable [74]. Phenylosazones of sugars are known to exist preponderantly in the acyclic form, and they show [75] the $\mathrm{C}=\mathrm{N}$ band at $6.3 \mu \mathrm{m}\left(1587 \mathrm{~cm}^{-1}\right)$.

Acyclic semicarbazones usually show a band at 5.97 to $6.08 \mu \mathrm{m}$ (1675 to $1645 \mathrm{~cm}^{-1}$ ) for $\mathrm{C}=\mathrm{N}$. Acyclic thiosemicarbazones show a weak band at 6.06 to $6.14 \mu \mathrm{m}\left(1650\right.$ to $\left.1630 \mathrm{~cm}^{-1}\right)$; the thiosemicarbazones of seven aldoses did not show this band, and were therefore considered to have a cyclic structure [76].

Cellulose I, II, and III differ in the amorphous and crystalline regions, and their spectra show differences in the $\mathrm{O}-\mathrm{H}$ stretching range. Thus, cellulose I shows [77] five bands in the OH region, and when cellulose film is treated $[78,79]$ with 
deuterium oxide vapor, the intensity of one of these, at 2.78 to $3.03 \mu \mathrm{m}\left(3600\right.$ to $\left.3000 \mathrm{~cm}^{-1}\right)$, rapidly decreases and an $\mathrm{O}-\mathrm{D}$ band at 3.70 to $4.17 \mu \mathrm{m}$ (2700 to $2400 \mathrm{~cm}^{-1}$ ) appears; the band affected is the $\mathrm{OH}$ stretching of the amorphous regions of the cellulose. The four bands that remain are those of hydrogen-bonded hydroxyl groups in the crystalline region. The ratio of the intensities of the $\mathrm{OH}$ and $\mathrm{OD}$ bands then gives an indication of the proportion of hydroxyl groups that are hydrogen-bonded in a crystalline manner, and this ratio thus provides a measure of the crystallinity $[80]$.

The directions of the hydroxyl groups in celluloses were determined by using plane-polarized, infrared radiation [81] (see sec. 6). It was shown that the $\mathrm{OH}$ band at $3.02 \mu \mathrm{m}\left(3309 \mathrm{~cm}^{-1}\right)$ is "perpendicular," and it was suggested that some of the hydroxyl bonds lie along the chain direction and form intramolecular hydrogen bonds.

The spectrum of starch indicates [82] that the hydroxyl groups are extensively hydrogen-bonded. The spectrum of potato starch differs from that of corn starch, especially in absorption regions for oxygen-containing groups. Thus, absorption is stronger [83] for the corn starch at $5.95 \mu \mathrm{m}$ (1681 $\left.\mathrm{cm}^{-1}\right), 9.5$ to $10.5 \mu \mathrm{m}\left(1053\right.$ to $\left.952 \mathrm{~cm}^{-1}\right)$, and 11.7 $\mu \mathrm{m}\left(855 \mathrm{~cm}^{-1}\right)$, whereas it is stronger for potato starch at $10.8 \mu \mathrm{m}\left(926 \mathrm{~cm}^{-1}\right)$. Arrow-root, corn, potato, rice, and wheat starches show bands at 3 $\mu \mathrm{m}\left(3333 \mathrm{~cm}^{-1}\right), 4.75 \mu \mathrm{m}\left(2105 \mathrm{~cm}^{-1}\right)$, and 6.15 $\mu \mathrm{m}\left(1626 \mathrm{~cm}^{-1}\right)$. When the water content of the starch is changed, the band at $3 \mu \mathrm{m}\left(3333 \mathrm{~cm}^{-1}\right)$ undergoes a change characteristic of the particular starch, and this property may be used for identifying and classifying starches [84].

\section{Special Techniques}

Plane-polarized radiation has proved useful in studying oriented films of such polysaccharides as cellulose, chitin, and xylan, providing information $[81,85]$ not given by other techniques. It has mainly been used in studying the crystal structure of samples having uniaxial orientation, as in fibers, in which the polymer chains are aligned along the fiber axis. The spectrum is measured with the radiation vector (a) parallel and (b) perpendicular to the chain direction. The respective intensity of the "parallel" and the "perpendicular" bands depends on the direction of the transition moment of the vibration responsible for the band, that is, whether it is mainly parallel or perpendicular to the chain direction. Thus, in the $\mathrm{C}-\mathrm{H}$ stretching region of 3.33 to $3.57 \mu \mathrm{m}$ (3000 to $2800 \mathrm{~cm}^{-1}$ ) of the spectrum of cellulose, there are a number of partially overlapping bands some of which cannot be assigned on the basis of group-frequency. The $\mathrm{C}-\mathrm{H}$ bonds of the ring are known to be approximately perpendicular to the chain axis, and so the dichroism of the bands associated with them must also be perpendicular; consequently, the perpendicular bands at $c a .3 .45$ $\mu \mathrm{m}\left(2900 \mathrm{~cm}^{-1}\right)$ have been assigned [86] to those vibrations. The cellulose band at $3.51 \mu \mathrm{m}$ (2853 $\mathrm{cm}^{-1}$ ) was assigned to the symmetrical stretch for $\mathrm{CH}_{2}$, and a band at $7.00 \mu \mathrm{m}\left(1430 \mathrm{~cm}^{-1}\right)$ to the $\mathrm{CH}_{2}$ symmetrical bending mode.

The direction of the bonds in a crystal may also be determined. $\alpha$-D-Glucopyranose shows one band at $2.94 \mu \mathrm{m}\left(3405 \mathrm{~cm}^{-1}\right)$ and four others in the region of 2.99 to $3.12 \mu \mathrm{m}$ (3347 to $3204 \mathrm{~cm}^{-1}$ ). These have been correlated [79] with the results of x-ray diffraction studies, which show [55] that there is one $\mathrm{O}-\mathrm{H} \cdots \mathrm{O}_{\mathrm{C}}^{\mathrm{C}}$ bond (between two molecules), and that there are four $\mathrm{O}-\mathrm{H}$ bonds. Similarly, the directions of the hydroxyl groups in sucrose have been determined [87].

The technique of attenuated total reflection [88] is useful for samples not amenable to examination by transmission spectroscopy; the radiation penetrates a short distance into the sample and is attenuated by absorption, and the extent of attenuation is independent of the thickness of the sample. For use with aqueous solutions, an attachment is placed in both beams of the spectrometer to compensate for absorption by water, making unnecessary the use of very thin, accurately matched cells to avoid interference by infrared absorption by water. The method has been applied [89] to the study of 20 carbohydrates in the region of 14.29 to $40.00 \mu \mathrm{m}$ (700 to $250 \mathrm{~cm}^{-1}$ ). For those compounds whose transmittance spectra in this region had previously been recorded $[12,13]$, the attenuated total reflection spectra were in good agreement. In this range, the anomers of a sugar afford different spectra.

The use of a micro-die for preparing alkali halide pellets, and of lead thiocyanate [which is water-soluble and gives a single band at 4.85 $\left.\mu \mathrm{m}\left(2062 \mathrm{~cm}^{-1}\right)\right]$ as an internal reference standard, permits identification and quantitative determination of micro quantities of water-soluble carbohydrates such as are obtained by paper chromatography [90].

Raman spectra, obtained with visible light, give the same kind of information as infrared spectra. The sample is irradiated with monochromatic light, and a very small fraction of the scattered light contains frequencies different from that of the source; these are characteristic of the molecule irradiated, and correspond closely in position, but not in intensity, to those in the infrared spectrum. For example, in the spectra of carboxylic acid dimers, the band for the $\mathrm{C}=\mathrm{O}$ symmetrical stretching mode occurs strongly at ca. $6.02 \mu \mathrm{m}\left(1660 \mathrm{~cm}^{-1}\right)$ in Raman spectra, but is very weak (not normally observed) in infrared spectra; in contrast, the band for the $\mathrm{C}=\mathrm{O}$ asymmetrical stretching mode, at $c a .5 .85 \mu \mathrm{m}$ $\left(1710 \mathrm{~cm}^{-1}\right)$, is weak in Raman, but very strong in infrared, spectra. Thus, Raman spectra supplement infrared spectra. Raman spectra have been 
studied for some 1,3-dioxolane compounds related to sugar acetals [91]. Introduction of the technique of laser Raman spectroscopy may be expected to lead to greater activity in this field.

\section{References}

[1] For extensive treatments of the theory and practice of infrared spectroscopy, see: F. A. Miller, in Organic Chemistry, An Advanced Treatise ( $H$. Gilman, Ed.), Vol. 3, Chapter 2, Wiley, New York, $1953 ;$ R. N. Jones and C. Sandorfy, in Chemical Applications of Spectroscopy; Technique of Organic Chemistry (W. West, Ed.), Vol. 9, Chapter 4, Interscience, New York, 1956; L. J. Bellamy, The Infra-red Spectra of Complex Molecules, 2nd ed., Wiley, New York, 1958; G. K. T. Conn and D. G. Avery, Infrared Methods: Principles and Applications, Academic Press, New York, 1960; K. Nakanishi, Practical Infrared Absorption Spectroscopy, Holden-Day, San Francisco, 1962; W. Brügel, An Introduction to Infrared Spectroscopy (translated from the German), Wiley, New York, 1962; W. J. Potts, Jr., Chemical Infrared Spectroscopy, Wiley, New York, 1963; C. N. R. Rao, Chemical Applications of Infrared Spectroscopy, Academic Press, New York, 1963; A. D. Cross, Introduction to Practical Infrared Spectroscopy, 2nd ed., Butterworth, Washington, D.C., 1964; R. G. White, Handbook of Industrial Infrared Analysis, Plenum Press, New York, 1964; N. B. Colthup, L. H. Daly, and S. E. Wiberly, Introduction to Infrared and Raman Spectroscopy, Academic Press, New York, 1964: H. A. Szymanski, IR Theory and Practice of Infrared Spectroscopy, Plenum Press, New York, 1964; J. R. Dyer, Applications of Absorption Spectroscopy of Organic Compounds, PrenticeHall, Englewood Cliffs, N.J., 1965.

[2] R. S. Tipson, A. S. Cerezo, V. Deulofeu, and A. Cohen, J. Research NBS 71 A, 53 (1967).

[3] S. A. Barker, E. J. Bourne, and D. H. Whiffen, Methods Biochem. Anal. 3, 213 (1956).

[4] R. S. Tipson, H. S. Isbell, and J. E. Stcwart, J. Research NBS 62, 257 (1959).

[5] L. P. Kuhn, J. Am. Chem. Soc. 74, 2492 (1952); 76, 4323 (1954).

[6] A. R. H. Cole and P. R. Jefferies, J. Chem. Soc. 1956, 4391.

[7] S. A. Barker, J. S. Brimacombe, A. B. Foster, D. H. Whiffen, and G. Zweif el, Tetrahedron $\%, 10(1959)$.

[8] V. C. Farmer, Spectrochim. Acta 8, 374 (1957).

[9] V. C. Farmer, Chem. Ind. (London) 1959, 1306.

[10] S. A. Barker, E. J. Bourne, H. Weigel, and D. H. Whiffen, Chem. Ind. (London) 1956, 318.

[11] S. A. Barker, E. J. Bourne, W. B. Neely, and D. H. Whiffen, Chem. Ind. (London) 1954, 1418.

[12] R. S. Tipson and H. S. Isbell, J. Research NBS 64A, $239(1960)$

[13] R. S. Tipson and H. S. Isbell, J. Research NBS 66A, 31 (1962).

[14] L. P. Kuhn, Anal. Chem. 22, 276 (1950).

[15] G. P. Ellis, J. Chem. Soc. (B) 1966, 572.

[16] American Petroleum Institute Project 44, Infrared Absorption Spectra, Data Distribution Office, Agricultural and Mechanical College of Texas, College Station, Texas 77843 (2440 spectra); American Society for Testing and Materials, 1916 Race St., Philadelphia, Pennsylvania 19103 (IBM cards; index to over 55,500 published spectra); The Documentation of Molecular Spectroscopy (DMS), Butterworth, Bethesda, Maryland 20014 (almost 200 sugar derivatives); H. M. Hershenson, Infrared Absorption Spectra, Indices for 1945-1957, and 1958-1962, Academic Press, New York, 1959 and 1964. National Research Council-National Bureau of Standards Catalog of Infrared Spectra and Bibliography, National Bureau of Standards, Washington, D.C. 20234 (punch cards), out of print; Ref. 2 [spectra of $23 \mathrm{~N}$-glycosylacylamides and 21 1,1-bis(acylamido)-1-deoxyalditols]; Ref. 4 (28 cyclic acetals of sugars); Ref. 12 (24 aldopyranosides); Ref. 13 (6 anomeric pairs of sugars and 12 single anomers); Ref. 14 (79 carbohydrates); Sadtler Research Laboratories, 3316 Spring Garden St., Philadelphia, Pennsylvania 19104 (about 200 sugar derivatives); H. A. Szymanski, Infrared Band Handbook, Plenum Press, New York, Vol. 1 (1964), Supplements 1 and 2 (1964), Vol. 2 (1966), Supplements 3 and 4 (1966); R. L. Whistler and L. R. House, Anal Chem. 25, 1463 (1953) (35 monosaccharides); J. W. White, Jr., C. R. Eddy, J. Petty, and N. Hoban, Anal. Chem. 30, 506 (1958) (10 disaccharides and their acetates).

[17] H. S. Isbell, F. A. Smith, E. C. Creitz, H. L. Frush, J. D. Moyer, and J. E. Stewart, J. Research NBS $59,41(1957) ; 56$ sugar acetates.

[18] R. S. Tipson and H. S. Isbell, J. Research NBS 64A, 405 (1960); 24 acetylated aldopyranosides.

[19] R. S. Tipson and H. S. Isbell, J. Research NBS 65A, 31 (1961); 8 reducing pyranose acetates and $11 \mathrm{~N}$-glycopyranosylacetamides.

[20] R. S. Tipson and H. S. Isbell, J. Research NBS 65A, 249 (1961); 20 peracetylated pyranoses.

[21] T. Urbański, W. Hofmann, and M. Witanowski, Bull. Acad. Polon. Sci. Ser. Chim. Geol. Geograph. \%, 619 (1959).

[22] D. H. Whiffen, Chem. Ind. (London) 195\%, 129.

[23] C. D. Hurd and H. Jenkins, Carbohyd. Res. 2, 240 (1966)

[24] D. Horton and J. M. J. Tronchet, Carbohyd. Res. 2, 315 (1966).

[25] H. B. Henbest, G. D. Meakins, B. Nicholls, and A. A. Wagland, J. Chem. Soc. 195\%, 1462.

[26] R. S. Tipson, J. Am. Chem. Soc. 74, 1354 (1952).

[27] R. D. Guthrie and H. Spedding, J. Chem. Soc. 1960, 953.

[28] R. S. Tipson and A. Cohen, Carbohyd. Res. 1, 338 (1966).

[29] M. Stacey, R. H. Moore, S. A. Barker, H. Weigel, E. J. Bourne, and D. H. Whiffen, Proc. U.N. Intern. Conf. Peaceful Uses At. Energy, 2nd, Geneva, 1958, 20, 251.

[30] J. S. Brimacombe, A. B. Foster, M. Stacey, and D. H. Whiffen, Tetrahedron 4, 351 (1958).

[31] B. Akermark, Acta Chem. Scand. 15, 985 (1961).

[32] R. S. Tipson, W. S. Layne, and A. Cohen, unpublished results (1962).

[33] R. Kübler, W. Lüttke, and S. Weckberlin, Z. Elektrochem. 64, 650 (1960); A. Rosenthal and M. R. S. Weir, J. Org. Chem. 28, 3025 (1963).

[34] P. Bassignana and C. Cogrossi, Tetrahedron 20, 2361 (1964).

[35] J. W. Rowen, F. H. Forziati, and R. E. Reeves, J. Am. Chem. Soc. 73, 4484 (1951).

[36] H. Spedding, J. Chem. Soc. 1960, 3147.

[37] M. L. Wolfrom and S. Hanessian, J. Org. Chcm. 27, $1800(1962)$.

[38] S. F. D. Orr, R. J. C. Harris, and B. Sylvén, Nature 169, 544 (1952); H. J. R. Stevenson and S. Levine, Science 116, 705 (1952); S. Levine, H. J. R. Stevenson, and P. W. Kabler, Arch. Biochem. Biophys. 45, 65 (1953).

[39] S. F. D. Orr, Biochim. Biophys. Acta 14, 173 (1954).

[40] S. A. Barker, E. J. Bourne, R. M. Pinkard, and D. H. Whiffen, Chem. Ind. (London) 1958, 658.

[41] See also, Y. Nitta, J. Ide, A. Momose, and M. Kawada, Yakugaku Zasshi 82, 790 (1962); Chem. Abstr. 5\%, 14601 (1962).

[42] R. Stephens, Ph. D. Thesis, University of Birmingham, England (1954).

[43] R. S. Tipson, J. Org. Chem. 26, 2462 (1961).

[44] L. Hough, J. E. Priddle, R. S. Theobald, G. R. Barker, T. Douglas, and J. W. Spoors, Chem. Ind. (London) 1960; 148. 
[45] W. M. Doane, B. S. Shasha, E. I. Stout, C. R. Russell, and C. E. Rist, Abstr. Papers Am. Chem. Soc. Meeting 153, 14c (1967).

[46] F. Micheel, F. P. van de Kamp, and H. Wulff, Chem. Ber. 88, 2011 (1955)

47] S. E. Darmon and K. M. Rudall, Discussions Faraday Soc. 9, 251 (1950).

[48] D. Horton and M. L. Wolfrom, J. Org. Chem. 27, 1794 (1962).

[49] A. G. Lloyd and K. S. Dodgson, Nature 184, 548 (1959).

[50] K. Onodera, S. Hirano, and N. Kashimura, Carbohyd. Res. 1, 208 (1965).

[51] E. Albano, D. Horton, and T. Tsuchiya, Carbohyd. Res. 2, 349 (1966).

[52] F. A. Carey, D. H. Ball, and L. Long, Jr., Carbohyd. Res. 3, 205 (1966).

[53] D. Horton and H. S. Prihar, Carbohyd. Res. 4, 115 (1967).

[54] P. J. Launer, Perkin-Elmer Instr. News 13 (3), 10 (1962).

[55] T. R. R. McDonald and C. A. Beevers, Acta Cryst. 5, 654 (1952)

[56] S. A. Barker, E. J. Bourne, M. Stacey, and D. H. Whiffen, J. Chem. Soc. 1954, 171.

57] S. A. Barker, E. J. Bourne, R. Stephens, and D. H Whiffen, J. Chem. Soc. 1954, 3468.

[58] S. A. Barker, E. J. Bourne, R. Stephens, and D. H Whiffen, J. Chem. Soc. 1954, 4211.

[59] S. A. Barker and R. Stephens, J. Chem. Soc. 1954, 4550 .

[60] L. M. J. Verstraeten, Anal. Chem. 36, 1040 (1964). See also, idem, Carbohyd. Res. 1, 481 (1966).

61] C. J. Brown, Acta Cryst. 13, 1049 (1960).

[62] A. G. Lloyd and K. S. Dodgson, Biochim. Biophys Acta 46, 116 (1961).

[63] D. A. Rees, J. Chem. Soc. 1963, 1821.

[64] H. S. Isbell and W. W. Pigman, J. Research NBS 18. 141 (1937).

[65] W. W. Pigman and H. S. Isbell, J. Research NBS 19. 189 (1937).

[66] S. J. Angyal and V. A. Pickles, Carbohyd. Res. 4, 269 (1967).

[67] F. S. Parker, Biochim. Biophys. Acta 42, 513 (1960).

[68] H. S. Isbell, J. E. Stewart, H. L. Frush, J. D. Moyer, and F. A. Smith, J. Research NBS 57, 179 (1956).
[69] H. B. Wood, Jr., and H. G. Fletcher, Jr., J. Am. Chem. Soc. 79, 3234 (1957).

[70] J. K. N. Jones and J. C. Turner, J. Chem. Soc. 1962, 4699

[71] A. E. El-Ashmawy and D. Horton, Carbohyd. Res. 1, 164 (1965).

[72] F. Legay, Compt. Rend. 234, 1612 (1952).

[73] H. Bredereck, A. Wagner, D. Hummel, and $H$. Kreiselmeier, Chem. Ber. 89, 1532 (1956).

[74] J. Fabian and M. Legrand, Bull. Soc. Chim. France 23, 1461 (1956); J. Fabian, M. Legrand, and P. Poirier, ibid. 23, 1499 (1956).

[75] W. Otting, Ann. 640, 44 (1961).

[76] J. R. Holker, cited in H. Spedding, Advan. Carbohydrate Chem. 19, 23 (1964); see p. 40 and footnote 51 on p. 37.

[77] L. Brown, P. Holliday, and I. F. Trotter, J. Chem. Soc. 1951, 1532

[78] K. E. Almin, Svensk Papperstid. 55, 767 (1952).

[79] H. J. Marrinan and J. Mann, J. Appl. Chem. (London) 4, 204 (1954)

[80] J. Mann and H. J. Marrinan, Trans. Faraday Soc. 52, 481, 487, 492 (1956).

[81] J. Mann and H. J. Marrinan, J. Polymer Sci. 27, 595 (1958); 32, 357 (1958); Mí. Tsuboi, ibid. 25, 159 (1957).

[82] M. Samec, Stärke 5, 105 (1953).

[83] M. Samec, J. Polymer Sci. 23, 801 (1957).

[84] O. Yovanovitch, Compt. Rend. 252, 2884 (1961)

[85] C. Y. Liang and R. H. Marchessault, J. Polymer Sci. 37, 385 (1959); 39, 269 (1959); 43, 85 (1960); F. G. Pearson, R. H. Marchessault, and C. Y. Liang, ibid. 43, 101 (1960); R. H. Marchessault and C. Y. Liang, ibid. 43, 71 (1960); 59, 357 (1962); R. H. Marchessault, F. G. Pearson, and C. Y. Liang, Biochim. Biophys. Acta 45, 499 (1960).

[86] R. H. Marchessault, Pure Appl. Chem. (London) 5, 107 (1962).

[87] J. W. Ellis and J. Bath, J. Chem. Phys. 6, 221 (1938).

[88] J. Fahrenfort, Spectrochim. Acta 17, 698 (1961).

[89] F. S. Parker and R. Ans, Appl. Spectry. 20, 384 (1966).

[90] F. E. Resnik, L. S. Harrow, J. C. Holmes, M. E. Bill, and F. L. Greene, Anal. Chem. 29, 1874 (1957).

[91] S. A. Barker, E. J. Bourne, R. M. Pinkard, and D. H. Whiffen, J. Chem. Soc. 1959, 802, 807. 




\section{NBS TECHNICAL PUBLICATIONS}

\section{PERIODICALS}

JOURNAL OF RESEARGH reports National Bureau of Standards research and development in physics, mathematics, chemistry, and engineering. Comprehensive scientific papers give complete details of the work, including laboratory data, experimental procedures, and theoretical and mathematical analyses. Illustrated with photographs, drawings, and charts.

\section{Published in three sections, available separately:}

\section{- Physics and Chemistry}

Papers of interest primarily to scientists working in these fields. This section covers a broad range of physical and chemical research, with major emphasis on standards of physical measurement, fundamental constants, and properties of matter. Issued six times a year. Annual subscription: Domestic, $\$ 5.00$; foreign, $\$ 6.00 *$.

\section{Mathematical Sciences}

Studies and compilations designed mainly for the mathematician and theoretical physicist. Topics in mathematical statistics, theory of experiment design, numerical analysis, theoretical physics and chemistry, logical design and programming of computers and computer systems. Short numerical tables. Issued quarterly. Annual subscription: Domestic, $\$ 2.25$; foreign, $\$ 2.75 *$.

\section{- Engineering and Instrumentation}

Reporting results of interest chiefly to the engineer and the applied scientist. This section includes many of the new developments in instrumentation resulting from the Bureau's work in physical measurement, data processing, and development of test methods. It will also cover some of the work in acoustics, applied mechanics, building research, and cryogenic engineering. Issued quarterly. Annual subscription: Domestic, $\$ 2.75$; foreign, $\$ 3.50^{*}$.

\section{TECHNICAL NEWS BULLETIN}

The best single source of information concerning the Bureau's research, developmental, cooperative and publication activities, this monthly publication is designed for the industry-oriented individual whose daily work involves intimate contact with science and technology-for engineers, chemists, physicists, research managers, product-development managers, and company executives. Annual subscription: Domestic, $\$ 1.50$; foreign, $\$ 2.25^{*}$.

- Difference in price is due to extra cost of foreign mailing.
NONPERIODICALS

Applied Mathematics Series.

Mathematical tables, manuals, and studies.

Building Science Series. Research results, test methods, and performance criteria of building materials, components, systems, and structures.

Handbooks. Recommended codes of engineering and industrial practice (including safety codes) developed in cooperation with interested industries, professional organizations, and regulatory bodies.

Special Publications. Proceedings of NBS conferences, bibliographies, annual reports, wall charts, pamphlets, etc.

Monographs. Major contributions to the technical literature on various subjects related to the Bureau's scientific and technical activities.

National Standard Reference Data Series. NSRDS provides quantitative data on the physical and chemical properties of materials, compiled from the world's literature and critically evaluated.

Product Standards. Provide requirements for sizes, types, quality and methods for testing various industrial products. These standards are developed cooperatively with interested Government and industry groups and provide the basis for common understanding of product characteristics for both buyers and sellers. Their use is voluntary.

Technical Notes. This series consists of communications and reports (covering both other agency and NBS-sponsored work) of limited or transitory interest.

\section{CLEARINGHOUSE}

The Clearinghouse for Federal Scientific and Technical Information, operated by NBS, supplies unclassified information related to Governmentgenerated science and technology in defense, space, atomic energy, and other national programs. For further information on Clearinghouse services, write:

Clearinghouse

U.S. Department of Commerce Springfield, Virginia 22151

Order NBS publications from: Superintendent of Documents Government Printing Office Washington, D.C. 20402 
UNITED STATES.

Government PRINTING OfFICE

DIVISION OF PUBLIC DOCUMENTS

WASHINGTON, D.C. 20402

OFFICIAL BUSINESS
POSTAGE AND FEES PAID

U.S. GOVERNMENT PRINTING OFFICE 




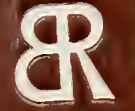

BEYHOLDS BWDEBZ, INC

JUNE1972 
